\title{
Modelling utility-aggregator-customer interactions in interruptible load programmes using non-cooperative game theory
}

\author{
Soheil Mohseni ${ }^{\mathrm{a}, ~}{ }^{*}$, Alan C. Brent ${ }^{\mathrm{a}, \mathrm{b}}$, Scott Kellyc, Will N. Browne ${ }^{\mathrm{a}}$, Daniel Burmester ${ }^{\mathrm{a}}$ \\ a Sustainable Energy Systems, School of Engineering and Computer Science, Faculty of Engineering, Victoria University of \\ Wellington, PO Box 600, Wellington, 6140, New Zealand \\ ${ }^{\mathrm{b}}$ Department of Industrial Engineering and the Centre for Renewable and Sustainable Energy Studies, Stellenbosch \\ University, Stellenbosch, 7600, South Africa \\ ${ }^{\mathrm{c}}$ Institute for Sustainable Futures, University of Technology Sydney, Sydney, NSW, 2007, Australia \\ ${ }^{*}$ Corresponding author, Email: soheil.mohseni@ecs.vuw.ac.nz
}

\begin{abstract}
Aggregator-activated demand response (DR) is widely recognised as a viable means for increasing the flexibility of renewable and sustainable energy systems (RSESs) necessary to accommodate a high penetration of variable renewables. To this end, by acting as DR aggregators and offering energy trading capabilities to smaller customers, energy retailers unlock additional sources of demand-side flexibility to ensure the cost-optimal operation of RSESs. Accordingly, a growing body of literature has highlighted the ways in which non-cooperative game theory could be used to reduce the gaps between modelled and real-world results for aggregator-mediated DR schemes. This paper aims to contribute to the trends of giving a realistic grounding to research on distributed DR-integrated energy scheduling by using insights from non-cooperative game theory to determine: (1) the optimal trade-off between importing electricity and utilising DR capacity in grid-tied RSESs, (2) the impact of the price elasticity of DR supply of different customer classes - especially, new sources of electricity demand, such as e-mobility on the system-level dispatch of DR resources, and (3) the financial implications of harnessing the flexibility potential of a large number of end-consumers across different sectors. Accordingly, the principal goal of the paper is to develop an operational planning optimisation model that can be directly applied to real-world aggregatormediated, market-based demand-side flexibility provisioning domains. To this end, this paper presents the first DR elasticity-aware, non-cooperative game-theoretic DR scheduling model that: (1) yields the best compromise solution between imported power and dispatched DR resources from the utility's perspective, (2) characterises the utility-aggregator-customer interactions during the market-based DR trade process with several customer categories involved, and (3) disaggregates the total sectoral load on the system to individual end-consumers, which has potential implications for pre-feasibility and business case assessments. The application of the model to a conceptual micro-grid for the town of Ohakune, in New Zealand, demonstrates its effectiveness in reducing the daily system operational cost by $\sim 66 \%$ and $\sim 47 \%$ on a representative summer and winter day, respectively. Importantly, the paper provides statistically significant evidence supporting that activating the flexibility potential of small- to medium-scale end-consumers through specifically defined third-party aggregators in a market-based approach - that is aware of strategic interactions among instrumentally rational economic agents involved in the dispatch and delivery of DR resources - plays a significant role in the cost-optimal transition to $100 \%$-renewable electricity generation systems within the smart grid paradigm.
\end{abstract}

Keywords: Micro-grid; Demand response; Energy management; Non-cooperative game theory; Stackelberg leadership

\begin{tabular}{|c|c|c|c|}
\hline \multicolumn{4}{|l|}{ Nomenclature } \\
\hline Acronyms & & $d_{c r}^{k, j}(t), d_{n c r}^{k, j}(t)$ & $\begin{array}{l}\text { critical/non-critical portion of the } \\
k \text {-th customer of the } j \text {-th } \\
\text { aggregator's original demand in } \\
\text { time } t[\mathrm{kWh}]\end{array}$ \\
\hline DERs & distributed energy resources & $d_{f u l l}^{k, j}(t)$ & $\begin{array}{l}\text { original demand of the } k \text {-th } \\
\text { customer signed up to aggregator } j \\
\text { in time } t[\mathrm{kWh}]\end{array}$ \\
\hline DR & demand response & $\underline{d_{n c r}^{k, j}, \overline{d_{n c r}^{k, j}}}$ & $\begin{array}{l}\text { lower/upper bound of the non- } \\
\text { critical portion of the customer- }\end{array}$ \\
\hline
\end{tabular}




\begin{tabular}{|c|c|c|c|}
\hline & & & $\begin{array}{l}\text { specific load demands of the } j \text {-th } \\
\text { aggregator }[\mathrm{kWh}]\end{array}$ \\
\hline DRA & demand response aggregator & $D_{d e f}(t)$ & $\begin{array}{l}\text { onsite power generation capacity } \\
\text { deficit to meet load demand in time } \\
t[\mathrm{kWh}]\end{array}$ \\
\hline DSM & demand-side management & $\begin{array}{l}d i s^{k, j, \min }, \\
d i s^{k, j, \max }\end{array}$ & $\begin{array}{l}\text { lower/upper bound of the } \\
\text { discomfort cost experienced by the } \\
k \text {-th customer of aggregator } j[\$]\end{array}$ \\
\hline EV & electric vehicle & $i_{M G O}$ & $\begin{array}{l}\text { Step length of the MG operator- } \\
\text { offered incentive price }[\$ / \mathrm{kWh}]\end{array}$ \\
\hline EaaS & energy-as-a-service & $I_{L A}^{j, \min }, I_{L A}^{j, \max }$ & $\begin{array}{l}\text { lower/upper bound of the incentive } \\
\text { price offered by aggregator } j \\
{[\$ / \mathrm{kWh}]}\end{array}$ \\
\hline MG & micro-grid & $I_{M G O}^{\min }, I_{M G O}^{\max }$ & $\begin{array}{l}\text { lower/upper bound of the } \mathrm{MG} \\
\text { operator-determined incentive } \\
\text { price }[\$ / \mathrm{kWh}]\end{array}$ \\
\hline MH & micro-hydro & $N_{\text {cust }}^{j}$ & $\begin{array}{l}\text { number of end-consumers } \\
\text { subscribed to aggregator } j\end{array}$ \\
\hline NIWA & $\begin{array}{l}\text { New Zealand's National } \\
\text { Institute of Water and } \\
\text { Atmospheric Research }\end{array}$ & $\pi_{i m}(t)$ & $\begin{array}{l}\text { wholesale electricity price in time } t \\
{[\$ / \mathrm{kWh}]}\end{array}$ \\
\hline PV & photovoltaic & $P a r_{\text {max }}^{j}$ & $\begin{array}{l}\text { maximum participation rate of end- } \\
\text { consumers enrolled with } \\
\text { aggregator } j[\%]\end{array}$ \\
\hline RESs & renewable energy sources & Variables & \\
\hline RSESs & $\begin{array}{l}\text { renewable and sustainable } \\
\text { energy systems }\end{array}$ & $d^{k, j}(t)$ & $\begin{array}{l}\text { DR supplied by end-customer } k \text { of } \\
\text { aggregator } j \text { in time } t[\mathrm{kWh}]\end{array}$ \\
\hline WT & wind turbine & $d^{k, j, *}(t)$ & $\begin{array}{l}\text { pure-strategy load reduction of } \\
\text { end-consumer } k \text { signed up to } \\
\text { aggregator } j \text { in time } t \text { [kWh] }\end{array}$ \\
\hline Sets and indices & & $D_{L A}^{j}(t)$ & $\begin{array}{l}\text { total DR supplied by aggregator } j \\
\text { in time } t[\mathrm{kWh}]\end{array}$ \\
\hline $\begin{array}{l}d^{-k, j, *} \\
=\left\{d^{1, j, *}, d^{2, j, *}, \ldots, d^{k-1, j, *},\right. \\
\left.\quad d^{k+1, j, *}, \ldots, d^{N_{j, j, *}}\right\}\end{array}$ & $\begin{array}{l}\text { set of DR supplied by the } \\
\text { customers subscribed to } \\
\text { aggregator } j \text { except the } k \text {-th } \\
\text { customer [kWh] }\end{array}$ & $D_{L A}^{j, *}(t)$ & $\begin{array}{l}\text { pure-strategy total DR supplied by } \\
\text { aggregator } j \text { in time } t[\mathrm{kWh}]\end{array}$ \\
\hline$D^{*}=\left\{d_{1}^{*}, d_{2}^{*}, \ldots, d_{K}^{*}\right\}$ & $\begin{array}{l}\text { set of pure-strategy customer- } \\
\text { supplied DR [kWh] }\end{array}$ & $d i s^{k, j}(t)$ & $\begin{array}{l}\text { discomfort cost imposed on end- } \\
\text { consumer } k \text { signed up to } \\
\text { aggregator } j \text { in time } t[\$]\end{array}$ \\
\hline$D_{L A}^{j, *}=\left\{d^{k, j, *}, d^{-k, j, *}\right\}$ & $\begin{array}{l}\text { set of pure-strategy customer- } \\
\text { supplied DR associated with } \\
\text { the } j \text {-th aggregator }[\mathrm{kWh}]\end{array}$ & $I_{L A}^{j}(t)$ & $\begin{array}{l}\text { incentive price posted by } \\
\text { aggregator } j \text { for load reduction in } \\
\text { time } t[\$ / \mathrm{kWh}]\end{array}$ \\
\hline $\begin{array}{l}I_{L A}^{*} \\
=\left\{I_{L A}^{1, *}, I_{L A}^{2, *}, I_{L A}^{3, *}, I_{L A}^{4, *}, I_{L A}^{5, *}\right\}\end{array}$ & $\begin{array}{l}\text { set of pure-strategy } \\
\text { aggregator-posted incentive } \\
\text { payments }[\$ / \mathrm{kWh}]\end{array}$ & $I_{L A}^{j, *}(t)$ & $\begin{array}{l}\text { pure-strategy incentive price } \\
\text { posted by aggregator } j \text { in time } t \\
{[\$ / \mathrm{kWh}]}\end{array}$ \\
\hline$K$ & $\begin{array}{l}\text { customers within the MG's } \\
\text { territory }\end{array}$ & $I_{M G O}(t)$ & $\begin{array}{l}\text { incentive price posted by the } \mathrm{MG} \\
\text { operator for load reduction in time } \\
t[\$ / \mathrm{kWh}]\end{array}$ \\
\hline$j \in J$ & demand response aggregators & $I_{M G O}^{*}(t)$ & $\begin{array}{l}\text { pure-strategy incentive price } \\
\text { posted by the MG operator for load } \\
\text { reduction in time } t[\$ / \mathrm{kWh}]\end{array}$ \\
\hline$k \in N_{J}$ & $\begin{array}{l}\text { customers subscribed to } \\
\text { aggregator } j\end{array}$ & $O C_{M G}(t)$ & $\begin{array}{l}\text { operational cost of addressing the } \\
\text { net energy deficit of the } \mathrm{MG} \text { in } \\
\text { time } t[\$]\end{array}$ \\
\hline Parameters & & $O C_{M G}^{*}(t)$ & $\begin{array}{l}\text { pure-strategy operational cost of } \\
\text { addressing the net energy deficit of } \\
\text { the MG in time } t[\$]\end{array}$ \\
\hline$c_{1}^{k, j}, c_{2}^{k, j}$ & $\begin{array}{l}\text { Customer-specific discomfort } \\
\text { factors }\end{array}$ & $P_{i m}(t)$ & $\begin{array}{l}\text { imported electricity by the } \mathrm{MG} \text { in } \\
\text { time } t[\mathrm{kWh}]\end{array}$ \\
\hline$\delta_{j}$ & $\begin{array}{l}\text { Sectoral elasticity of DR } \\
\text { supply }\end{array}$ & $\operatorname{Pr}_{L A}^{j}(t)$ & profit of aggregator $j$ in time $t[\$]$ \\
\hline
\end{tabular}




\section{Introduction}

Smart electrification with renewables is set to play a pivotal role in accelerating the transition to the low-carbon economy [1]. However, renewable energy sources (RESs) are collectively plagued by unpredictability and variability of supply [2], [3]. This is especially problematic during daily peak times when demand is highest [4]. On the other hand, the increased electrification of end-uses - such as transport, space heating, and water heating - is a key contributor to rising these peaks, which results in the need for over-capacity of renewable supplies and/or (capital-intensive) storage devices, as well as additional transmission and distribution network capacity [5].

Accordingly, a key challenge in realising cost-effective electric power systems with high penetrations of nondispatchable (variable) RESs is the temporal discrepancy between renewable power generation and peak power demand [6]. Addressing this challenge in grid-connected renewable and sustainable energy systems (RSESs) requires an optimal trade-off between imported power demand from the upstream grid and reduced peak demand through demand-side management (DSM) strategies for cost-optimal operations [7]. In this light, utilising the flexibility potential of small- to medium-scale customers - as part of the goal of tapping all available sources of demand-side flexibility - is of utmost importance to reduce the cost of integrating high shares of renewables and the need to invest in network capacity reinforcement, especially under future scenarios of end-use sector coupling [8].

The recent emergence of advanced control methods, founded on two-way communications for smart grid applications, has facilitated the coordination of small- to medium-scale demand response (DR) resources previously invisible to grid operators - through a new family of load-serving entities, called DR aggregators (DRAs). The DRAs act as intermediaries between utilities and retail consumers by aggregating loads of the same class and packaging the total DR bids for submission in ancillary services markets [9]. In this context, the largescale deployment of retail DSM services is recognised as one of the critical enablers of the low-carbon economy [10].

To this end, it is commonly accepted that [11]: (1) open aggregator-mediated DSM marketplaces improve customer engagement due to the additional flexibility provided to the subscribers, while supporting the minimum expected utilities by end-consumers, and (2) the wholesale electricity prices need to be valued as a primary means of signalling the worth of load reduction to the utility when developing load shifting and/or curtailment strategies.

In general, DR programmes can be classified into two main categories: price- and incentive-based. Price-based DR involves time-variant pricing schemes to reflect the value of electricity in different time periods. On the other hand, in incentive-based DR schemes, customers are offered incentive payments to reduce their energy use in case of grid reliability problems or high wholesale prices [12], [13]. The interruptible/curtailable services, which fall in the category of incentive-based programmes, are selected in this study for the modelling of aggregator-mediated DR events, which provides for voluntary customer enrolments and responses. That is, customers are given the discretion to select their level of participation in any DR event.

Additionally, DR programmes can be implemented over a broad range of timescales, from 15 minutes (real-time operation) to several years (system planning) ahead of schedule [13]. Among these timescales, the day-ahead energy management analysis is considered in this paper as it has a considerable potential to benefit from marketbased DR programmes. This represents a unique scheduling horizon due to the availability of high-quality weather-dependent renewable power generation forecasts.

\subsection{Incorporating strategic interactions into demand response scheduling models}

To reduce the gaps between modelled and real-world results for aggregator-mediated DR schemes, it is necessary to characterise the economic interactions between the utility, DRAs, and end-consumers. To this end, the 
simplifying assumptions commonly applied in designing aggregator-mediated DR programmes, which are not justified in many cases, need to be avoided [14]. More specifically, a realistic grounding needs to be given to research on aggregator-mediated DR procurement to improve the quality and accuracy of the day-ahead DR supply capacity forecasts. Accordingly, to be able to directly apply the aggregator-mediated DR frameworks to real-world problems, it is crucial to model the involved active economic agents - the utility, DRAs, and endconsumers - as rational, self-interested agents who make decentralised and utility-maximising decisions. Under this assumption, the problem of aggregator-mediated DR planning falls in the realm of algorithmic game theory [15] and, more particularly, algorithmic mechanism design [16]. Mechanism design models the interaction of individuals using tools borrowed from game theory, where the institutions governing interactions are modelled as mechanisms, in strategic settings, where players act rationally [17]. The overall aim of mechanism design within the context of this study is to derive an economically stable allocation of DR resources in that a truthful preference report is the best strategy for every active economic agent involved.

On the other hand, market-driven incentive-based DR resources are often procured through "ascending bid" auctions in that the incentive price is successively increased in rounds until the level of procured DR units minimises the system operational cost [18]. This characteristic can be modelled by the Stackelberg leadership model [19], which is a model of imperfect competition founded on sequential non-cooperative games [20], in which the market leader moves first and then the followers move sequentially. Accordingly, the aggregatormediated DR procurement game can be modelled as a two-stage feedback game in which the utility and DRAs form a Stackelberg problem in the first stage, while the DRAs and end-consumers form another Stackelberg problem in the second stage. More specifically, the DRAs serve as the followers of the utility in wholesale DSM market and, at the same time, the leaders of the sector-specific retail DSM markets, where end-consumers act as followers [21].

\subsection{Game-theoretic models applied to demand-side management studies}

Several review studies have emphasised the important role that the characterisation of the strategic rationality of economic agents involved in the delivery of DR resources can play in making simulation more perceptually representative of real-world scenarios [22], [23], [24]. To this end, as discussed in the previous sub-section, noncooperative game theory [20] has been recognised as a standard analytical tool to understand the strategic economic behaviour of rational entities that interact through efficient and stable markets for the activation of smaller DR units - and make predictable and reproducible choices [25].

The Stackelberg, non-cooperative game-theoretic DR scheduling problems in the literature can be classified broadly into three groups, which focus on:

- Deriving a strategic bidding strategy for the aggregators of the storage capacity to participate in the wholesale DSM market;

- Characterising the direct interactions between large-scale customers and the utilities in the wholesale DSM market; and

- Modelling the utility-aggregator-customer interactions across both the wholesale and retail DSM markets.

The first of the three strands of the literature focuses on determining the optimal bidding strategy for communityscale energy storage aggregators in day-ahead DR markets - to provide flexibility services to the grid - using insights from Stackelberg, non-cooperative game theory. Reihani et al. [26] were among the first to design a Stackelberg, non-cooperative game-theoretic DR market framework for energy storage aggregators to sell a joint capacity of smaller DR units to the utility, whilst accounting for the incentive price elasticity of aggregatormediated DR capacity. Following their seminal study, several other studies have developed conceptual models of Stackelberg competition among DRAs to sell energy stored in energy storage devices of their customers based on non-cooperative game theory in a market-driven context. For instance, Motalleb and Ghorbani [27] have developed a game-theoretic DR market design with incomplete information. Specifically, the DRAs adaptively bid on the market using a Bayesian approach to maximise their expected payoffs, while the DR market is cleared according to the Nash equilibrium of the DRAs' strategies. The authors have gone further in [28] and proposed a real-time DR market design, which uses a repeated game-theoretic framework with incomplete-information to find the market equilibrium in a competitive environment, where the DRAs aim to maximise their payoffs from selling aggregated DR products, namely: the energy stored in residential batteries. Similarly, Liu et al. [29] have formalised a Bayesian strategic game approach to optimally leverage the demand-side flexibility potential in multi-community local areas, whilst dealing with incomplete information about the exact forms of aggregate discomfort functions the representatives of the communities (who serve as load aggregators) are seeking to minimise. 
In another instance, Sharifi et al. [30] have developed a single-leader, multi-follower Stackelberg strategic bidding model to assist the associated DRA decision-making process in building the optimal aggregate demand bidding curve for submission to the day-ahead electricity market. Based on the numeric simulation results, the authors have shown the effectiveness of the model in increasing the profit of a representative DRA who participates in the day-ahead electricity market by as much as 6.4\%. Similarly, Shafiekhani et al. [31] have devised a bi-level, Stackelberg, multi-criteria approach considering profit and emissions objectives to support the optimal bidding strategy of a virtual power plant that aggregates a set of small-scale interruptible loads and distributed energy resources (DERs) for participation in pool-based day-ahead and real-time electricity markets. Moghimi and Barforoushi [32] have also put forward a mixed-integer linear programming formulation to determine the optimal pool strategy of a price-maker distribution company integrating smaller DR products based on a real-time pricing scheme, whilst sequentially coordinating the wholesale and retail markets. Furthermore, Rayati et al. [33] have formalised a non-cooperative game-theoretic framework to adequately model the strategic interactions of DRAs, who constitute a balancing group within the context of European electricity markets, where the balancing group representative is responsible for the net imbalances of the associated portfolio of generation and/or demand. Moreover, Dadashi et al. [34] have formulated a bi-level, stochastic game-theoretic model to solve the short-term decision-making problem on the optimal volumes of energy imports for each hour of the next day in the presence of a single DRA. Based on the numerical simulation results, they have demonstrated the effectiveness of their framework in yielding an equilibrium DR dispatch solution, where the profits of the utility and the DRA are increased by $\sim 6 \%$ and $\sim 70 \%$, respectively, compared to a business-as-usual approach. Salyani et al. [35] have also utilised non-cooperative game theory to characterise the interactions between a distribution company and electric vehicle $(\mathrm{EV})$ stations that provide coordinated charging/discharging services. By integrating the proposed DR dispatch game into a standard, exact mathematical optimisation-based energy planning model, and applying it to the IEEE 33-bus distribution test system, they have highlighted the significant role of game-theoretic DR scheduling in minimising reality gaps.

Fernandez et al. [36] have also proposed a game-theoretic DSM framework, where end-consumers share their private information with a central control agent who aggregates the scheduling preferences of the end-consumers and bids into the wholesale market. Based on the real-world simulation results obtained from the application of their proposed framework to the energy management problem of a neighbourhood in Sydney, Australia, the authors have demonstrated the effectiveness of their framework in reducing the daily peak-to-average ratio by $\sim 9 \%$ on a representative winter day. Similarly, Abapour et al. [11] have formulated a non-cooperative gametheoretic modelling framework for DRAs in DSM markets. Based on the numeric simulation results obtained by applying their proposed model to a real test-case, the authors have demonstrated that characterising the associated behavioural traits in the supply of aggregated DR is able to increase the profit gained by the distribution system operator by up to a maximum of 7\%. The authors go further in [37] and adopt a Bayesian approach to handling incomplete information of the players about the future moves of their opponents, which improves the accuracy of market equilibrium points predicted by non-cooperative game-theoretic models. In another instance, Fan et al. [38] have put forward a bargaining-based cooperative energy trading mechanism for a distribution company and DRAs. Based on the numeric test-case results, the authors have demonstrated the efficacy of their Nash bargaining-based method in reducing the daily peak-to-average ratio of load profile by up to a maximum of around $9 \%$. Song et al. [39] have also studied the optimal day-ahead bidding strategies of DRAs, whilst additionally using fuzzy membership functions to address the uncertainty associated with the heterogeneous willingness of end-users to participate in DR activities. By applying the model to a community housing complex, comprising 3,000 residential dwellings, they have shown the effectiveness of the model in increasing the DRAs' profits by up to $\sim 71 \%$. Moreover, Chen et al. [40] have proposed an iterative distributed algorithm to address the strategic interactions between a distribution system operator and several DRAs in its service territory, formulated as a noncooperative game-theoretic DR dispatch problem, and demonstrated a relative error of less than 3\% compared to counterpart analytically-derived solutions. The main advantages of the iterative distributed algorithm over closedform solutions are: (i) revealing only necessary information about the customers' incentive-directed load interruption decisions (driven by the customers' marginal utilities of supplying DR capacities) while preserving privacy, and (ii) handling high-degree non-linearities often present in the players' payoff functions without the need for making several simplifying assumptions that potentially impair the solution quality.

The second strand of the literature focuses on characterising the interactions between larger industrial and commercial customers and utilities in DR programmes, which have been operating for many years, using Stackelberg game-theoretic frameworks. For instance, Nwulu and Xia [41] have proposed a game-theoretic DR programme, which determines the optimal hourly incentive rate to be offered to large-scale end-consumers, who have signed up for load curtailment services, by maximising the utility's payoff function. Based on the numeric simulation results, the authors have shown that their proposed model is able to reduce the total load demand over a 24 -h timeframe by up to $\sim 17 \%$. The authors have also improved their proposed model in [42] by adding a closedloop model predictive controller and demonstrated its effectiveness in eliciting a further load reduction and improving the utility's total daily payoff. 
Although the ideas that fall under this strand of the literature are most meaningful when dealing with large-scale customers, there are some instances that model the interactions between smaller customers and utilities without aggregator mediation. For instance, Fan [43] has formulated a game-theoretic framework to characterise the interactions between a utility and EV owners, who aim to cost-optimally charge the batteries in their EVs. Also, Chai et al. [44] have put forward a non-cooperative game-theoretic DSM market model for the interactions of multiple utility companies and multiple end-consumers. Based on the results obtained from an illustrative testcase, the authors have demonstrated that their proposed model is able to improve the social welfare index by up to $\sim 6 \%$ for a 24 -hour day-ahead timeframe. Furthermore, Tang et al. [45] have developed a game-theoretic model to address the strategic interactions between a utility grid and several building complexes who opt to supply their DR flexibility products. The authors have demonstrated the efficacy of their proposed model in reducing the buildings' energy bills by up to a maximum of $8.3 \%$, whilst additionally reducing the fluctuations in forecasted demand by about $40 \%$.

In another instance, Guo et al. [46] have proposed a non-cooperative game-theoretic approach with two-sided incomplete information for clearing the spot electricity markets where specific mechanisms allow for DR capacities to be bid into them. By applying the model to a hypothetical case example, the authors have demonstrated the superiority of their proposed model to the business-as-usual approaches in terms of maximising social welfare. In a marked departure from the existing literature, Guo et al. [47] go further and apply their proposed method to DR-integrated block bidding markets, where the total electricity demand is divided into multiple blocks and the auction is processed block by block, each with an individual market-clearing price, in contrast to the traditional hourly pricing model. Similarly, Golmohamadi et al. [48] have formulated a multi-agentbased scheduling framework for trading residential and industrial flexibility procured through DRAs in electricity markets. Moreover, Pal et al. [49] have developed a strategic Stackelberg game-theoretic framework that produces the unique, pure-strategy Nash equilibrium of the DR scheduling game played between the distribution system operator and a set of residential end-users. The numeric simulation results have demonstrated the utility of the proposed model in reducing the peak-to-average ratio by a significant $31.4 \%$, while supporting a fair allocation of benefits - derived from the utilisation of DR flexibility resources - among the participants. Also, Tavakkoli et al. [50] have formalised a single-leader-multi-follower non-cooperative game to minimise system-wide supplydemand mismatches, whilst simultaneously maximising customer utilities for delivering the flexibility capacities of their heating, ventilation, and air conditioning (HVAC) systems. Based on the numerical simulation results obtained from the application of the proposed method to an incentive-based curtailable load programme in a residential area of 70 houses (as followers), they have demonstrated its efficacy in mitigating supply-demand mismatches by up to a significant $\sim 43 \%$.

While the first and second strands of the literature characterise the interactions between utilities and DRAs, or between utilities and individual end-users, the third strand of the literature expands the boundaries of noncooperative game-theoretic DR market and enables a more integrative approach to DSM planning. In particular, this strand of the literature seeks to address how to achieve economically stable and efficient divisions of the surplus created by load curtailments based on non-cooperative game theory. In this context, the standard approach is to develop a two-stage (dual-loop) DR market design in that the utility and DRAs compete in the top-level (wholesale) DSM market, where the utility offers load reduction incentive prices to the DRAs, who offer a percentage of the utility-offered incentive rates to their end-consumers in the bottom-level (retail) DSM market. For instance, Yu and Hong [21] have formulated a two-loop Stackelberg game for an incentive-based, marketdriven, aggregator-mediated scheduling of interruptible DR resources. Based on the numeric simulation results, the authors have confirmed the superiority of their proposed model in terms of reducing the hourly operational cost of a distribution grid by circa $47 \%$, as compared to the case where generation capacity deficits are addressed purely by onsite diesel generators. The authors have additionally applied their model to another test-case including medium-scale industrial customers and reaffirmed their findings. Notably, they have shown the ability of their proposed model in reducing the hourly operational cost of a typical distribution network including medium-sized industrial customers by up to around $63 \%$.

In another instance, Ren et al. [51] have proposed an optimal Stackelberg energy scheduling framework specifically tailored to the coordination of the interactions between the distribution network, EV aggregators (that combine the participating individual interruptible EV charging loads), and EV owners. The modelling framework accounts for the individual objectives of the three sets of the involved players, and is shown to be able to yield a participation rate of 99\% in EV load management programs. Şengör et al. [52] go further by characterising the uncertainties associated with the EV charging behaviours, while optimising the strategic bidding strategy of an aggregator participating in day-ahead and secondary control reserve markets. Zhong et al. [53] have also put forward a coupon incentive-based DR scheme, where third-party load-serving entities participate in the wholesale DSM market and offer a flat incentive rate to the small-scale customers subscribed to them. Accordingly, they have proposed an algorithm to find the optimum coupon incentive price with respect to different wholesale market conditions. Also, Sobhani et al. [54] have modelled the interactions between several interconnected energy hubs - the operators of which essentially serve as DRAs - as a congestion game, whilst adhering to the associated coupling constraints. They have shown the existence and uniqueness of the pure-strategy Nash equilibrium of the developed non-cooperative game-theoretic model that is aware of the discomfort patterns of end-consumers, 
whilst additionally producing the numerical Nash equilibrium solution of the game using a specifically developed distributed algorithm for real-world applications.

Furthermore, Feng et al. [55] have proposed a bi-level Stackelberg non-cooperative game-theoretic model that is able to produce the Nash equilibrium of a transactive energy market where a set of independent DRAs compete to maximise their objective functions in the lower level. On the other hand, the upper level deals with updating a transactive incentive price signal sent to the DRAs in an iterative approach so as to cost-optimally meet the distribution system operator requirements, whilst maximising the social welfare with respect to the locational marginal price. Vuelvas et al. [56] have additionally analysed the incentive-compatibility of aggregator-mediated incentive-based DSM schemes. To this end, the authors have formulated a two-stage stochastic programming problem for the strategic interactions between DRAs and end-consumers and solved it using ideas from game theory. Moreover, Gazafroudi et al. [57] have provided evidence of the effectiveness of an 'agent-based' noncooperative game-theoretic approach to managing the smaller DR products, in terms of providing a sustainable platform for trading small- to medium-sized DR products under both individual rationality and collective rationality conditions in sequential games - which ensures the strategic stability of the equilibrium solution. Also, Li et al. [58] employ a Stackelberg, non-cooperative game-theoretic framework to optimally dispatch energy hubs equipped with multi-energy DR resources, where demand-side flexibility capacities elicited from electrical and thermal loads are separately aggregated.

\subsection{Day-ahead, aggregator-mediated demand response scheduling: Research gaps and questions}

The day-ahead, aggregator-mediated DR scheduling literature has convincingly shown the significance of characterising the strategic, interactive rationality of the players involved in exploiting the flexibility potential of smaller customers using Stackelberg, non-cooperative games in general. Yet, despite this achievement, there are still some previously unexplored considerations, which need to be factored into the analysis of aggregatormediated DR scheduling - to give a more realistic grounding to the research in this area. More specifically, three crucial aspects necessary to better reflect reality, while characterising the utility-aggregator-customer interactions, have not yet been addressed in the mainstream Stackelberg, non-cooperative game-theoretic DSM literature, namely:

1. Lack of an optimal trade-off analysis from the utility's perspective between importing power and exploiting DR resources: Although the potential benefits of characterising the strategic interactions between the utility, DRAs, and end-consumers has been demonstrated in several instances, no study, as far as can be ascertained, has developed a systematic framework to facilitate the decision-making process for utilities to find the best compromise between importing electricity and procuring load reductions. This raises the question to what extent producing such an optimal trade-off solution is able to reduce the operational cost of the utility, with the answer to this question implying potential consequences for renewable energy system design optimisation.

2. Poor understanding of the incentive-price elasticity of customer-supplied DR capacity across different sectors: While nearly all the reviewed studies consider the discomfort cost imposed on end-consumers due to load reduction as a decision criterion, elasticity of supply of DR capacity is seldom accounted for in the DSM planning models. It is of paramount importance for the utility to understand how the willingness of customer-supplied DR capacity differs across different end-use categories - especially in the face of new sources of electricity demand, such as the electrification of the transport sector. The research question following from this gap is how an effective model can be designed to limit the use of DR resources from each sector to an economically viable level.

3. Insufficiency of the number of considered end-consumers to be a suitable representative of real-world practice: Whilst considerable effort has been devoted to developing a range of non-cooperative gametheoretic, aggregator-mediated DR interventions to reduce or shift energy use, the number of small-sized customer samples cannot be considered representative of a real distribution system. More specifically, the set of end-consumers in previous studies on the aggregator-mediated DSM has never, as far as can be ascertained, been comprised of more than a handful of customers. Hence, a research question arises as to how community-scale energy systems can benefit from such schemes. This is especially relevant when conducting pre-feasibility analyses of RSESs, where forecasts of the total load demand on the system are available, but there is no mechanism to allocate the total load to a certain number of endconsumers.

\subsection{Objective}

The objective of the paper is to improve and expand the existing Stackelberg, non-cooperative game-theoretic, aggregator-mediated DR scheduling models, so that they can be more readily applied to the real energy management problems posed by utility companies, DRAs, and end-consumers alike. It contributes to the trend of broadening the DRA-mediated DSM problem to include the interactions between all the involved active economic agents in the game - the utility, DRAs, and end-consumers - evident in the literature review in sub-section 1.2. 
Specifically, this paper presents a novel two-stage, day-ahead, market-driven, incentive-based, aggregatormediated Stackelberg, game-theoretic DSM model, featuring the following key contributions, each filling one of the three knowledge gaps identified in the previous section, namely:

1. Founded on the interruptible/curtailable services, a robust bi-level decision support model is developed to assist the associated DR scheduling decision-making process for grid-tied RSESs. Notably, by producing the optimal trade-offs between importing power and employing DR flexibility resources for the hours of the next day for which a net energy deficit is predicted, the model is able to derive implications for the cost-optimal planning of RSESs.

2. The load type-specific price elasticity of DR supply is effectively captured in the model, enabling it to more accurately forecast the participation rate of different customer classes, namely: residential, commercial, industrial, agricultural, and EV-charging loads. To this end, in addition to demonstrating the existence and uniqueness of a closed-form solution to the derived game-theoretic DSM problem, an iterative distributed algorithm is developed to approximate the Nash equilibrium point with minimum information exchange, with the aim of preserving the private preferences of players.

3. The model incorporates a stochastic load disaggregation technique, which randomly breaks down the forecasted total sectoral electricity consumption into any specified number of end-users. This feature makes the model applicable to a wider range of settings, including pre-feasibility studies where no smart meter data are available. Accordingly, the application of the model to large numbers of end-consumers spread across a distribution network is able to improve the understanding of diverse sector-wide customer behaviours based on a broader set of end-consumers' strategies and the corresponding payoff profiles.

\subsection{Paper structure}

The remainder of this paper is structured as follows. Section 2 states the problem and describes the overall architecture and underlying assumptions of the model before mathematically defining the proposed noncooperative game-theoretic, aggregator-mediated DSM model. The case study is detailed in Section 3 before the numerical simulation results are presented and discussed in Section 4. Finally, conclusions are made and areas of further work are identified in Section 5.

\section{Game-theoretic, market-driven, incentive-based demand response programme}

The optimal scheduling of flexible demand-side resources can be classified as a multi-decision-maker problem, which is not amenable to business-as-usual, centralised, non-behaviour-aware treatments if the behavioural risk factors affecting the supply of DR services are to be characterised - to improve the reliability and validity of DSM business models.

\subsection{Aggregator-mediated demand response procurement as a Stackelberg, non-cooperative game}

The Stackelberg, strategic (non-cooperative) game concept [59] can provide a systematic framework to unveil the hidden relationships between the targeted incentive-driven load reductions and what would be achieved in practice provided that there are no penalties for non-compliance with the grid operator orders - in an attempt to make explicit the assumptions underlying the core concepts of the discipline. Non-cooperative game theory centres on the study of independent, rational decision-making in circumstances of strategic interaction (conflict) to achieve the Nash equilibrium [60]. That is, it furnishes the opportunity to analyse the DR arrangements based on ordinal information, rather than conventional cardinal information. Compared to the cardinal analysis, the ordinal analysis of a decision-making process is less subjected to 'knowledge' uncertainty so long as the sequential order of the process remains unchanged [61]. The key components of an aggregator-mediated, incentive-based DSM programme include: (1) energy service providers, DRAs, and customers, (2) incentive plans, and (3) customer performance (participation rates). These respectively correspond to the core elements of a non-cooperative game: (1) players, (2) strategies, and (3) payoffs from potential consequences, where the set of consequences reflects the outcome of every possible combination of available strategies of players. Such resemblances of the DSM planning and the associated strategic game are illustrated in Fig. 1. 


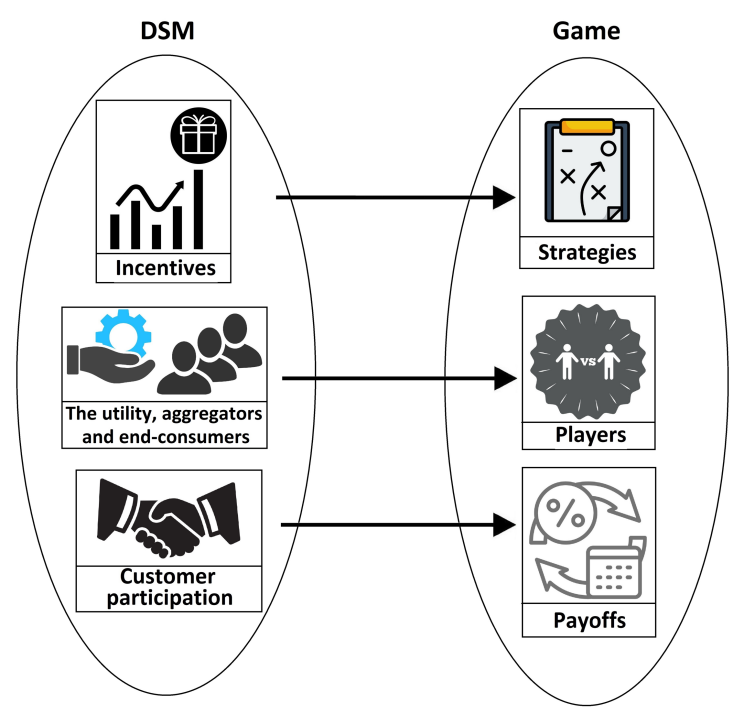

Fig. 1. One-to-one correspondence of an incentive-driven DR programme's elements to the fundamentals of non-cooperative game theory.

As discussed in Section 1, the Stackelberg competition [62] is a leadership model in finance, in which the leader entity moves first and then the follower entities move in sequence. From a game theory perspective, the players of such a game compete on quantity, and therefore it falls under the category of non-cooperative games. The core assumptions behind the Stackelberg competition models are as follows [63]: (1) the leader is aware ex-ante that the followers notice its moves; and (2) the followers have perfect information about, and react rationally to, changes in strategies taken by the leader. Along the same line as the Stackelberg competition model, the incentivebased approaches of implementing DR programmes start by offering financial incentives to end-users in return for load reductions, where the incentive prices and customer participation rates are determined by the market mechanism of seeking to maximise profit (or utility). It is also worth pointing out that it is proven that a Stackelberg, strategic game can be solved to obtain the Nash equilibrium, given every follower plays its bestresponse strategy to the leader's best action [64]. As the foregoing discussion indicates, the market-oriented, incentive-driven DR plans can be analysed through the framework of a Stackelberg, non-cooperative game via strategic market interactions.

\subsection{Proposed Stackelberg, non-cooperative game framework to model interruptible demand response}

The interruptible load programme is employed in this study as the DR service provision framework due to its unique advantage in providing a cost-effective means of improving the system's robustness against variability inherent in weather patterns. In this light, the proposed game-theoretic DR scheduling structure serves as a forum to implement the day-ahead interruptible load programme. The required quantity of interruptible loads at each time-step of the system operation is procured by the system operator in a day-ahead reserves market using a specifically developed procurement system that co-optimises the imported power from the national grid and the exploited capacity of DR resources.

To this end, after introducing different players involved in the game, this sub-section mathematically models the proposed Stackelberg, strategic game framework to leverage the potential of flexible DR resources for the dayahead operational scheduling of micro-grids (MGs), which promotes fair competition among different parties involved in the provision of DSM services. It then verifies the existence and uniqueness of an analytical solution to the developed game. However, to preserve the privacy of players, an iterative distributed algorithm is presented to obtain the Nash equilibrium of the game before describing the sequence of operations carried out to implement the proposed game-theoretic framework. The sequence of operations details the process of information exchange between different entities involved in the game.

The proposed game-theoretic formulation of the incentive-based DSM plans in this paper is specifically adapted for application to the day-ahead DR resource forecasting as part of the operational scheduling problem of MGs. The proposed framework also leverages the potential advantages of integrating flexible load aggregators into the DR market - with the twin goals of achieving scale as well as improving market competitiveness and liquidity. 


\subsubsection{Players of the game}

As shown in Fig. 2, the game is played with three distinct sets of players, namely: MG operator, responsive load aggregators, and different classes of end-consumers - residential, commercial, industrial, agricultural, and electrified transport. The MG operator is assumed to be an entity belonging to the utility providing electricity service to the considered case study area, which has full ownership of the MG assets and seeks to alleviate the load on the MG in predicted periods of peak energy use. As a principal element of the model, the day-ahead, hourly-basis forecasts of wholesale prices, load demand, and non-dispatchable renewable power generation capacity are assumed to be available based on the MG system state estimation studies. Responsive load aggregators act as intermediary agents between the utility and customers, as described in sub-section 1.2. Energy customers, which are placed at the lowest level of the proposed hierarchical architecture, modify their habitual energy consumption trends to take the best advantage of the financial incentives offered by the aggregator they have subscribed to. An overview of the proposed game-theoretic framework to schedule the incentive-driven DR resources through market interactions is shown in Fig. 2. Note that all the players were assumed to be rational, risk-neutral, utility-maximising, and myopic. ${ }^{1}$

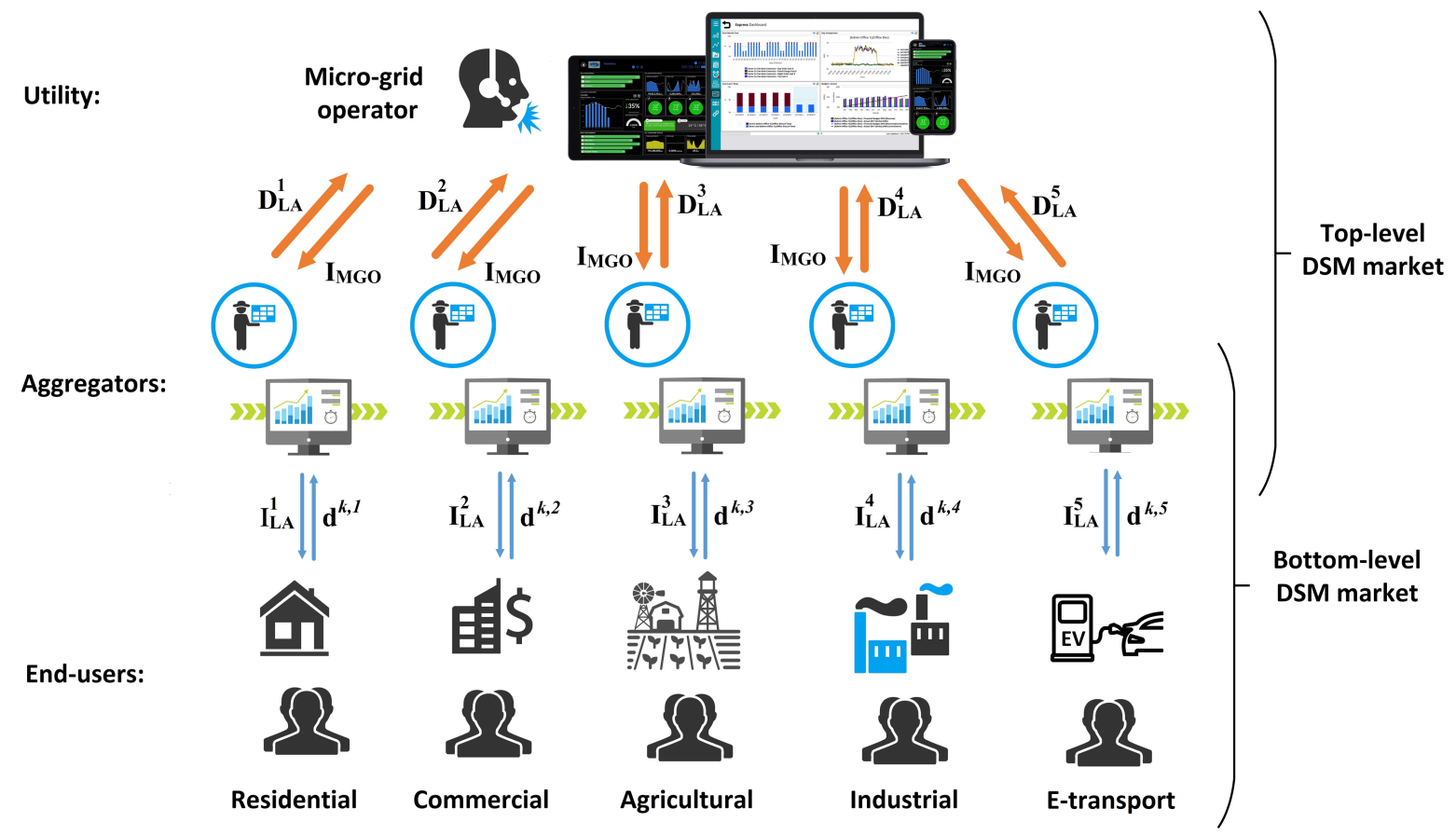

Fig. 2. Overview of the developed Stackelberg, strategic game framework to model the market-driven, incentive-based, aggregator-mediated demand response.

\subsubsection{Mathematical model of the utility}

In the face of an estimated internal power generation capacity deficit to meet the loads at the $t$-th time-step of operating the MG, $D_{\text {def }}(t)$, the MG operator attempts to balance out supply and demand by purchasing power from the upstream grid and/or offering financial incentives for load reduction. Accordingly, the objective function of the operator is to minimise the hourly-basis operational cost of offsetting power deficit, as described by Eq. (1), while adhering to constraints in Eqs. (2)-(4).

$$
\begin{gathered}
\min O C_{M G}(t)=\operatorname{cost}_{i m}(t)+I_{M G O}(t) \cdot \sum_{j \in J} D_{L A}^{j}(t) \forall t, \\
I_{M G O}^{\min } \leq I_{M G O}(t) \leq I_{M G O}^{\max } \forall t
\end{gathered}
$$

\footnotetext{
${ }^{1}$ Myopic behaviour means that players do not examine how their bids might influence the bids of other players in future iterations [15].
} 


$$
\begin{gathered}
D_{\text {def }}(t)=P_{i m}(t)+\sum_{j \in J} D_{L A}^{j}(t) \forall t, \\
\operatorname{cost}_{i m}(t)=\pi_{i m}(t) \cdot P_{i m}(t) \forall t,
\end{gathered}
$$

where $I_{M G O}(t)$ represents the rate of incentive payment for load reduction offered by the utility in time $t$ of the day-ahead MG scheduling; $I_{M G O}^{\min }$ and $I_{M G O}^{\max }$ respectively represent the lower and upper bounds of $I_{M G O} ; D_{L A}^{j}$ is the amount of load reduction contributed by the $j$-th aggregator, which is a member of the set of aggregators containing $|J|$ members; $\operatorname{cost}_{i m}$ is the cost of importing power from the national grid; $\pi_{i m}$ is the wholesale power price; and $P_{i m}$ denotes the imported power.

\subsubsection{Mathematical model of the aggregators}

As mentioned earlier, responsive load aggregation agents join the flexible demand resources of the same type to make them tractable in the capacity market and make them become price-makers, not price-takers. In this context, each aggregator aims to maximise its net profit to be gained by paying less financial incentives to its subscribers than what it receives from the utility, which is expressed by Eq. (5) subject to Eqs. (6) and (7).

$$
\begin{gathered}
\max P r_{L A}^{j}(t)=\left(I_{M G O}(t)-I_{L A}^{j}(t)\right) \cdot D_{L A}^{j}(t) \forall j, t, \\
I_{L A}^{j, \min } \leq I_{L A}^{j}(t) \leq I_{L A}^{j, \max } \forall j, t, \\
D_{L A}^{j}(t)=\sum_{k \in N_{J}} d^{k, j}(t) \forall j, t
\end{gathered}
$$

where $I_{L A}^{j}$ is the incentive payment offered by the $j$-th aggregator, $d^{k, j}$ is the amount of load reduction provided by the $k$-th customer serviced by the $j$-th aggregator, $N_{J}$ represents the set of customers who have subscribed to the $j$-th aggregator, while $I_{L A}^{j, \min }$ and $I_{L A}^{j, m a x}$ denote the lower and upper bounds of the incentive rates offered by the $j$-th aggregator, respectively.

\subsubsection{Mathematical model of the customers}

The main goal of the end-users of the MG system is to maximise their utility on the financial incentive programmes offered by their corresponding aggregators, whilst simultaneously keeping their comfort levels above certain thresholds, which is expressed by Eq. (8) subject to Eqs. (9) and (10).

$$
\begin{gathered}
\max U^{k, j}(t)=d^{k, j}(t) \cdot I_{L A}^{j}(t)-d i s^{k, j}(t) \forall k, t, \\
0 \leq d^{k, j}(t) \leq d_{n c r}^{k, j}(t) \forall k, t, \\
d_{\text {full }}^{k, j}(t)=d_{c r}^{k, j}(t)+d_{n c r}^{k, j}(t) \forall k, t,
\end{gathered}
$$

where the term $\left(d^{k, j}(t) . I_{L A}^{j}(t)\right)$ indicates the amount of financial incentive received by the $k$-th customer of the $j$-th aggregator in return for experiencing the discomfort level to the value of $d i s^{k, j}$, which is translated into cost by Eq. (11) [65], [66]; $d_{f u l l}^{k, j}$ and $d_{n c r}^{k, j}$ respectively denote the original load demand and the non-critical portion of the original load demand; while $d_{c r}^{k, j}$ represents the critical portion of the original load demand, which cannot be interrupted under any circumstances. In this study, the administrative customer baselines are used to measure the amounts of load reduction, which are represented by $d^{k, j}$ in the model.

$$
d i s^{k, j}=c_{1}^{k, j} \cdot\left(d^{k, j}\right)^{2}+c_{2}^{k, j} \cdot\left(1-\delta_{j}\right) \cdot d^{k, j} \forall k, t,
$$

where $c_{1}^{k, j}$ and $c_{2}^{k, j}$ are customer-specific (positive) coefficients, which reflect the customers' attitude with regard to load interruption as a function of financial incentive offers, while $\delta_{j}$ is a load type-dependent factor, which represents the willingness of different categories of customers in contributing to load reduction with values in the range $[0,1]$.

As constrained by Eq. (12), the discomfort cost to end-users must always meet the customers' expectations. 


$$
d i s^{k, j, \min } \leq \operatorname{dis}^{k, j} \leq \operatorname{dis}^{k, j, \max } \forall k, t,
$$

where $d i s^{k, j, \min }$ and $d i s^{k, j, \max }$ represent the minimum and maximum limits of discomfort cost experienced by each participant in the DR events, respectively.

Furthermore, as could be expected, the greater the values of $c_{1}^{k, j}$ and $c_{2}^{k, j}$, the greater the discomfort cost of load interruption, whereas the greater the value of $\delta_{j}$, the greater the willingness of the customer of type $j$ to participate in the load reduction programmes. For the most willing customers to enrol in the DSM programmes, $\delta_{j} \rightarrow 1$, whereas for the least willing customers, $\delta_{j} \rightarrow 0$.

\subsection{Stochastic load disaggregation}

It is assumed that the total energy use forecasts are available for each energy consumption sector, which contains a certain number of end-users, over a 24-h day-ahead timeframe. However, the individual end-consumers' hourly demand data are not available and need to be estimated by disaggregating the total sector-wise energy consumption data over each hour of the system's operation. To this end, a stochastic algorithm is employed to determine the load share of each energy customer over each hour of the day-ahead energy consumption data stream. The stochastic algorithm is built on seven parameters, namely: the load-type dependent estimates of the DR supply elasticity, $\delta_{j}$; the customer-specific willingness to supply DR capacity, characterised by $c_{1}^{k, j}$ and $c_{2}^{k, j}$; the full load demanded by each customer, $d_{f u l l}^{k, j}$, and its and non-critical portion, $d_{n c r}^{k, j}$; the maximum participation rate of different consumer categories in the incentive-directed DR programmes, Par $_{\text {max }}^{j}$; as well as the number of customers in each load type cluster, $N_{\text {cust }}^{j}=\left|N_{J}\right|$. More specifically, the stochastic algorithm generates $j$ random $N_{c u s t}^{j}$-element vectors of reduced load values, $\left[d^{1, j}, d^{2, j}, \ldots, d^{N_{c u s t}^{j}}, j\right]$, each with a fixed sum determined by the share of load category $j$ in the total load reduction, which is controlled by $\delta_{j}$, while adhering to the constraint in Eq. (13) [67]. Also, it is noteworthy that the parameter $P a r_{\text {max }}^{j}$ in the algorithm serves the purpose of defining the upper limit of $d_{n c r}^{k, j}$, as expressed in Eq. (14). Furthermore, the randomly selected $c_{1}^{k, j}$ and $c_{2}^{k, j}$ values characterise the DR supply decisions of individual end-consumers with respect to the aggregator-offered incentive rates in the algorithm.

$$
\begin{gathered}
\frac{d_{n c r}^{k, j}}{} \leq d^{k, j} \leq \overline{d_{n c r}^{k, j}}, \\
d_{n c r}^{k, j} \leq \operatorname{Par}_{\text {max }}^{j} \times d_{f u l l}^{k, j},
\end{gathered}
$$

where $d_{n c r}^{k, j}$ and $\overline{d_{n c r}^{k, j}}$ respectively denote the lower and upper bounds of the non-critical portion of the customerspecific loads subscribed to the $j$-th aggregator.

Fig. 3 shows a flowchart of the employed stochastic algorithm to synthetically disaggregate the total load reduction capacity procured by the proposed incentive-based DR programme into individual end-users who subscribe to the programme. First, the values of sectoral elasticities of customer-supplied DR capacities, $\delta_{j}$, sector-specific maximum participation rates, $P a r_{\text {max }}^{j}$, the number of customers in each load category, $N_{c u s t}^{j}$, sector-wide lower bounds of the non-critical portions of full load demands (available load interruption capacities of end-users), $\underline{d_{n c r}^{k, j}}$, the DRA-offered incentive price for load reduction, $I_{L A}^{j}$, the forecasted share of each load category in the total load demand, the expected total sectoral load interruptions, as well as the sectoral ranges of discomfort factors and full loads, are loaded as input data. For each load category, the algorithm then synthesises $N_{\text {cust }}^{j}$-element vectors of full load by normalising the uniformly-distributed random numbers generated in the interval $(0,1)$ using the MATLAB 'rand' function - which represent the original (non-reduced) loads of sector-wide customers - to fall within the pre-defined allowable range and scaling them so that their sum is equal to the total sectoral load demand forecasted. As the figure shows, if the associated condition is not met, the process of random full load generation for the sectoral customers is iterated until no synthesised load is outside the pre-defined range. After recording the synthesised full loads across all sectors, customer-specific discomfort factors are randomly generated and normalised to lie within the pre-specified ranges. Then, based on the generated discomfort factors, best-strategy load reductions of the participating end-users of each sector are derived. The calculated interruptible loads are then normalised to fit the customer-type-specific allowable range, and also scaled so that their sum is 
It should be noted that the stochastic algorithm is implemented for each hour of the next day for which a net energy deficit is predicted and is embedded within the main distributed algorithm (Algorithm 1) developed to determine the unique, pure-strategy Nash equilibrium of the day-ahead, non-cooperative DR dispatch game (see sub-section 2.2.4). It is also noteworthy that the employed disaggregation mechanism is not required for model implementation in real-world practice, as it is used only as a means to synthetically generate individual-level energy demand and DR supply capacity.

\subsubsection{Mathematical formulation of the game}

As shown in Fig. 4, the proposed dual-loop framework, which establishes a two-level strategic, day-ahead DSM market game for decision-making regarding the optimal dispatch of flexible DR resources is driven by two separate types of financial incentive offers: (1) those provided by the utility (MG operator) at the top (wholesale) level, and (2) those proposed by load aggregators at the bottom (retail or downstream) level. The operatorprovided incentive rates would directly impact the aggregate load reduction provided by the aggregation agents and, by the same token, the aggregator-provided incentive rates have a direct influence on the participation of end-users in the interruptive load management programmes. Looking from the inside out, the financial incentives offered by the utility/aggregators evolve with reference to the aggregators'/customers' responses to different levels of the offered incentive rates - and, in this sense, the devised framework is an intertwined system with a negative feedback loop. The DRAs in the proposed dual-loop, Stackelberg game-theoretic model, represented in Fig. 4, would have a twofold purpose: they act as the followers of the utility in the top-level loop, whilst, at the same time, leading the bottom-level loop, where end-users serve as final followers.

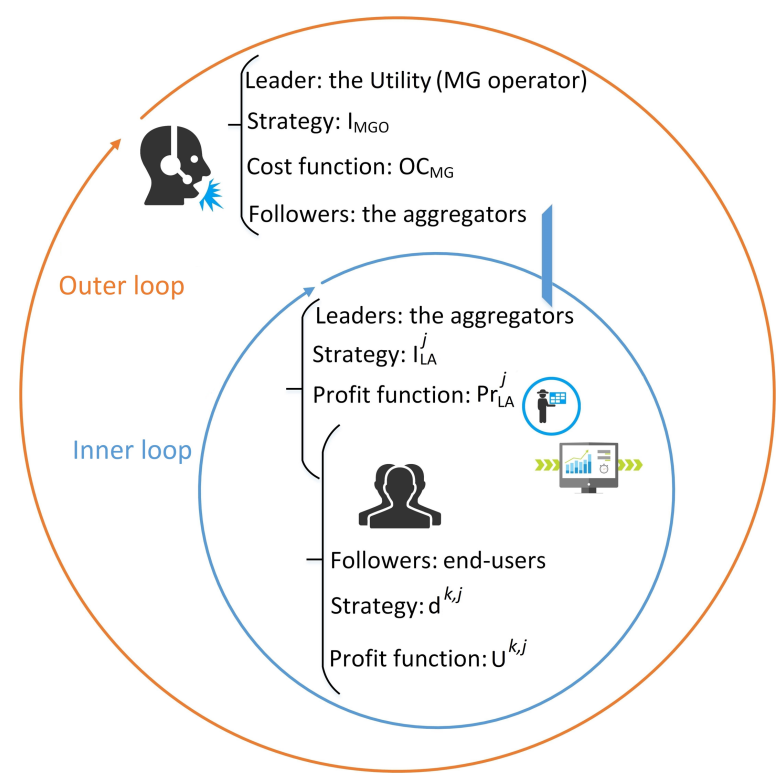

Fig. 4. Two-loop structure of the proposed Stackelberg game-theoretic DR management framework.

For the dual-loop, Stackelberg game-theoretic DR provision framework modelled above, a finite set of pure strategies $\left(I_{M G O}^{*}, I_{L A}^{*}, D^{*}\right)$ establish the pure-strategy Nash equilibrium of the game, if, and only if, the following inequality constraints are relaxed:

$$
\begin{aligned}
& O C_{M G}\left(I_{M G O}^{*}, I_{L A}^{*}, D^{*}\right) \leq O C_{M G}\left(I_{M G O}, I_{L A}^{*}, D^{*}\right), \\
& \operatorname{Pr}_{L A}^{j}\left(I_{M G O}^{*}, I_{L A}^{j, *}, D_{L A}^{j, *}\right) \geq \operatorname{Pr}_{L A}^{j}\left(I_{M G O}^{*}, I_{L A}^{j}, D_{L A}^{j, *}\right) \quad \forall j, \\
& U^{k, j}\left(d^{k, j, *}, I_{L A}^{j, *}\right) \geq U^{k, j}\left(d^{k, j}, d^{-k, j, *}, I_{L A}^{j, *}\right) \quad \forall k,
\end{aligned}
$$

where $I_{L A}^{*}=\left\{I_{L A}^{1, *}, I_{L A}^{2, *}, I_{L A}^{3, *}, I_{L A}^{4, *}, I_{L A}^{5, *}\right\}$ represents the union of pure strategies taken by all aggregators; $D^{*}=$ $\left\{d_{1}^{*}, d_{2}^{*}, \ldots, d_{K}^{*}\right\}$ denotes the union of pure strategies taken by the customers subscribed to each aggregator $j \in J$, where $K$ is the number of all the customers of the MG; $d^{k, j, *}$ represents the pure strategy taken by the $k$-th customer subscribed to the $j$-th aggregator; $d^{-k, j, *}=\left\{d^{1, j, *}, d^{2, j, *}, \ldots, d^{k-1, j, *}, d^{k+1, j, *}, \ldots, d^{N_{j}, j, *}\right\}$ denotes the set 
of pure strategies of all the customers of the $j$-th aggregator except its $k$-th customer; while $D_{L A}^{j, *}=\left\{d^{k, j, *}, d^{-k, j, *}\right\}$ identifies the pure strategies of all the customers signed up to the $j$-th aggregator.

The constraints in Eqs. (15)-(17) ensure that at the Nash equilibrium of the game, neither the MG's operational cost, nor the aggregators' profits, nor the customers' utilities can be further improved by taking a different strategy. As the next sub-section demonstrates, the developed dual-loop, Stackelberg, strategic game has a unique, purestrategy Nash equilibrium solution, at which no player can improve its payoff without reducing the payoff to at least one other player.

\subsubsection{Existence and uniqueness of the Nash equilibrium}

In view of the hierarchical structure of the proposed game-theoretic model for the provision of DR resources, backward induction can be utilised to identify the Nash equilibrium point. To this end, first, the best-response strategies of the end-users to the aggregator-provided incentive prices have to be determined as part of the inner loop of the game. The second step is to determine the aggregators' best strategies, while the last step is to examine the existence of the best strategy for the MG operator in the outer loop of the game, laid out in Fig. 4. The following theorem provides the necessary and sufficient conditions for the existence and uniqueness of a Nash equilibrium point for the devised game-theoretic model.

Theorem 1. There exists a unique, pure-strategy Nash equilibrium solution to the devised dual-loop, Stackelberg, non-cooperative game-theoretic framework for implementing the proposed customer utility-preserving, system state-aware, incentive-based load demand interruption programme, at which no player can obtain a higher level of payoff by deviating from its best strategy.

\section{Proof.}

(1) Determine the best strategies of the end-users, $d^{k, j, *}$, in response to the incentive payments offered by their corresponding aggregators for load reduction, $I_{L A}^{j}$, by taking the first-order derivative of $U^{k, j}$, given in Eq. (8), with respect to the amount of load reductions they provide, and then setting them equal to zero, as follows:

$$
\begin{gathered}
\frac{\partial U^{k, j}}{\partial d^{k, j}}=I_{L A}^{j}-\left(2 c_{1}^{k, j} \cdot d^{k, j}+c_{2}^{k, j} \cdot\left(1-\delta_{j}\right)\right)=0, \\
d^{k, j, *}=\frac{I_{L A}^{j}-c_{2}^{k, j} \cdot\left(1-\delta_{j}\right)}{2 c_{1}^{k, j}} .
\end{gathered}
$$

Then, the second-order derivative of $U^{k, j}$ can be obtained as:

$$
\frac{\partial^{2} U^{k, j}}{\partial\left(d^{k, j}\right)^{2}}=-2 c_{1}^{k, j}<0
$$

Given the positive value of $c_{1}^{k, j}$, the second-order derivative of $U^{k, j}$ is strictly negative, which implies that $U^{k, j}$ is strictly concave over the feasible region of $d^{k, j}$. Hence, the best-response strategies of the end-users, derived in Eq. (19), are guaranteed to return the unique, globally-optimum solutions.

(2) Identify the best strategies of the aggregators, $I_{L A}^{j, *}$, using the backward induction approach by substituting the best strategies of the end-users, given in Eq. (19), into Eq. (5), as follows:

$$
\begin{aligned}
P r_{L A}^{j} & =\left(I_{M G O}-I_{L A}^{j}\right) \cdot \sum_{k \in N_{J}} \frac{I_{L A}^{j}-c_{2}^{k, j} \cdot\left(1-\delta_{j}\right)}{2 c_{1}^{k, j}}=-\left(I_{L A}^{j}\right)^{2} \cdot \sum_{k \in N_{J}} \frac{1}{2 c_{1}^{k, j}} \\
& +I_{L A}^{j} \cdot\left(\sum_{k \in N_{J}} \frac{c_{2}^{k, j} \cdot\left(1-\delta_{j}\right)}{2 c_{1}^{k, j}}+\sum_{k \in N_{J}} \frac{I_{M G O}}{2 c_{1}^{k, j}}\right)+I_{M G O} \cdot \sum_{k \in N_{J}} \frac{-c_{2}^{k, j} \cdot\left(1-\delta_{j}\right)}{2 c_{1}^{k, j}} .
\end{aligned}
$$

Taking the first-order derivate of $P r_{L A}^{j}$, given in Eq. (21), with respect to the amount of financial incentives offered by the aggregators and then setting it equal to zero, the best strategies of the aggregators can be obtained as: 


$$
\begin{gathered}
\frac{\partial P r_{L A}^{j}}{\partial I_{L A}^{j}}=-I_{L A}^{j} \sum_{k \in N_{J}} \frac{1}{c_{1}^{k, j}}+\left(\sum_{k \in N_{J}} \frac{c_{2}^{k, j} \cdot\left(1-\delta_{j}\right)}{2 c_{1}^{k, j}}+\sum_{k \in N_{J}} \frac{I_{M G O}}{2 c_{1}^{k, j}}\right)=0, \\
I_{L A}^{j, *}=\frac{\left(\sum_{k \in N_{J}} \frac{c_{2}^{k, j} \cdot\left(1-\delta_{j}\right)}{2 c_{1}^{k, j}}+\sum_{k \in N_{J}} \frac{I_{M G O}}{2 c_{1}^{k, j}}\right)}{\sum_{k \in N_{J}} \frac{1}{c_{1}^{k, j}}}=\frac{1}{2} \sum_{k \in N_{J}} c_{2}^{k, j} \cdot\left(1-\delta_{j}\right)+\frac{1}{2} I_{M G O} .
\end{gathered}
$$

It is worthwhile noting that the aggregators' best strategies, derived in Eq. (23), are reflective of the elasticity of customer-supplied DR capacity, whilst additionally relying on the utility's best strategy - a mechanism consistent with the fundamental purposes of the aggregators.

Furthermore, the second-order derivative of $P r_{L A}^{j}$ can be obtained as:

$$
\frac{\partial^{2} P r_{L A}^{j}}{\partial\left(I_{L A}^{j}\right)^{2}}=-\sum_{k \in N_{J}} \frac{1}{c_{1}^{k, j}}<0
$$

Given the positive value of $c_{1}^{k, j}$, the second-order derivative of $P r_{L A}^{j}$ is strictly negative, which implies that $P r_{L A}^{j}$ is strictly concave over the feasible region of $I_{L A}^{j}$; therefore, the best strategies of the aggregators, given in Eq. (23), are guaranteed to yield the globally-optimum solutions.

(3) Verify the existence and uniqueness of the MG operator's best strategy by the following steps:

Substituting the best strategies of the aggregators, given in Eq. (23), into the best-response strategies of the customers, provided in Eq. (19), yields:

$$
\begin{aligned}
d^{k, j, *} & =\frac{\left(\frac{1}{2} \sum_{k \in N_{J}} c_{2}^{k, j} \cdot\left(1-\delta_{j}\right)+\frac{1}{2} I_{M G O}\right)-c_{2}^{k, j} \cdot\left(1-\delta_{j}\right)}{2 c_{1}^{k, j}} \\
& =\left(\frac{1}{4 c_{1}^{k, j}} \cdot \sum_{k \in N_{J}} c_{2}^{k, j} \cdot\left(1-\delta_{j}\right)\right)+\frac{1}{4 c_{1}^{k, j}} \cdot I_{M G O}-\frac{c_{2}^{k, j} \cdot\left(1-\delta_{j}\right)}{2 c_{1}^{k, j}} .
\end{aligned}
$$

Accordingly, the aggregated load reduction of each aggregator can be calculated as:

$$
\begin{aligned}
D_{L A}^{j, *}=\sum_{k \in N_{J}} d^{k, j, *} & =\left(\frac{I_{M G O}}{4} \cdot \sum_{k \in N_{J}} \frac{1}{c_{1}^{k, j}}\right)+\left(\frac{1}{4} \sum_{k \in N_{J}} \frac{c_{2}^{k, j} \cdot\left(1-\delta_{j}\right)}{c_{1}^{k, j}}\right) \\
& -\frac{1}{2} \sum_{k \in N_{J}} \frac{c_{2}^{k, j} \cdot\left(1-\delta_{j}\right)}{c_{1}^{k, j}}=\frac{I_{M G O}}{4} \cdot \sum_{k \in N_{J}} \frac{1}{c_{1}^{k, j}}-\frac{1}{4} \sum_{k \in N_{J}} \frac{c_{2}^{k, j} \cdot\left(1-\delta_{j}\right)}{c_{1}^{k, j}} .
\end{aligned}
$$

Then, the total amount of load reduction provided by all the aggregators can be expressed as:

$$
\sum_{j \in J} D_{L A}^{j, *}=\sum_{j \in J} \sum_{k \in N_{J}} d^{k, j, *}=\frac{I_{M G O}}{4} \cdot \sum_{j \in J} \sum_{k \in N_{J}} \frac{1}{c_{1}^{k, j}}-\frac{1}{4} \sum_{j \in J} \sum_{k \in N_{J}} \frac{c_{2}^{k, j} \cdot\left(1-\delta_{j}\right)}{c_{1}^{k, j}} .
$$

For the sake of simplicity, let $\alpha=\sum_{j \in J} \sum_{k \in N_{J}} \frac{1}{c_{1}^{k, j}}>0$ and $\beta=\sum_{j \in J} \sum_{k \in N_{J}} \frac{-c_{2}^{k, j} \cdot\left(1-\delta_{j}\right)}{c_{1}^{k, j}}>0$. Accordingly, Eq. (27) can be simplified to the following equation:

$$
\sum_{j \in J} D_{L A}^{j, *}=\frac{I_{M G O}}{4} \cdot \alpha+\frac{1}{4} \beta .
$$

Substituting Eqs. (3), (4), and (28) into the operational cost imposed on the utility to meet the onsite power generation capacity deficit, presented in Eq. (1), gives: 


$$
\begin{aligned}
O C_{M G} & =\pi_{i m} \cdot P_{i m}+I_{M G O} \cdot\left(\frac{I_{M G O}}{4} \cdot \alpha+\frac{1}{4} \beta\right) \\
& =\pi_{i m} \cdot\left(D_{d e f}-\left(\sum_{j \in J} D_{L A}^{j, *}\right)\right)+\frac{\alpha}{4} \cdot I_{M G O}{ }^{2}+\frac{\beta}{4} \cdot I_{M G O} \\
& =\pi_{i m} \cdot\left(D_{d e f}-\left(\frac{I_{M G O}}{4} \cdot \alpha+\frac{1}{4} \beta\right)\right)+\frac{\alpha}{4} \cdot I_{M G O}{ }^{2}+\frac{\beta}{4} \cdot I_{M G O} \\
& =\frac{\alpha}{4} \cdot I_{M G O}{ }^{2}+\left(\frac{\beta-\pi_{i m} \cdot \alpha}{4}\right) \cdot I_{M G O}+\pi_{i m} \cdot D_{d e f}-\frac{\pi_{i m} \cdot \beta}{4} .
\end{aligned}
$$

The first- and second-order derivatives of the re-formulated operational cost of meeting the onsite power generation capacity deficit with respect to the utility-offered financial incentives can be obtained as follows:

$$
\begin{gathered}
\frac{\partial O C_{M G}}{\partial I_{M G O}}=\frac{\alpha}{2} \cdot I_{M G O}+\left(\frac{\beta-\pi_{i m} \cdot \alpha}{4}\right), \\
\frac{\partial^{2} O C_{M G}}{\partial\left(I_{M G O}\right)^{2}}=\frac{\alpha}{2}>0 .
\end{gathered}
$$

Given the positive value of the second-order derivative of $O C_{M G}$, it can be deduced that it is a strictly convex function of $I_{M G O}$. Setting the first-order derivative of $O C_{M G}$, given in Eq. (30), equal to zero, the globally-optimum and, at the same time, the unique best strategy of the MG operator can be determined as follows:

$$
I_{M G O}^{*}=\frac{\pi_{i m} \cdot \alpha-\beta}{2 \alpha} .
$$

When the MG operator's pure strategy is identified, it can be substituted into Eq. (23) to find the pure strategies of the aggregators. Consequently, the best-response strategy of each end-user can be calculated by substituting the unique, globally-optimum incentive rate offered by the aggregator it is enrolled with, expressed in Eq. (23), into Eq. (19). Finally, the vector of the identified best strategies $\left(I_{M G O}^{*}, I_{L A}^{j, *}, d^{k, j, *}\right)$ represents the pure-strategy Nash equilibrium of the devised dual-loop, Stackelberg game and, thus, the proof of Theorem 1 is complete.

\subsubsection{Distributed algorithm}

The pure-strategy Nash equilibrium of the dual-loop, Stackelberg, non-cooperative game, derived analytically in the previous sub-section, is subject to privacy criticisms; the derived backward induction-based optimal solution finds the pure strategy of the MG operator assuming that the utility has complete information about the game. However, this is not a commonplace, accepted practice. Not only might this result in destructive strategies from the utility that subvert, rather than uphold, the social welfare, it would also put the privacy of customers at risk. To address these shortcomings, a distributed algorithm is derived in this sub-section to iteratively approximate the Nash equilibrium solution to the devised game. Nevertheless, it is still assumed that aggregators are trusted agents of customers playing on the same side of the line at the top level (outer loop) of the proposed dual-loop game, shown in Fig. 4. Accordingly, the distributed algorithm, derived in Algorithm 1, serves as the ultimate framework to obtain the Nash equilibrium solution set of the game. The fundamental principle of the algorithm is to iteratively update the amount of incentive price offered by the utility - as the wholesale-market-maker - from $I_{M G O}^{\min }$ to $I_{M G O}^{\max }$, and then determine the optimal incentive price offered by each aggregator and the participation rate (i.e. load demand reduction) of the customers enrolled with each aggregator using a distributed variant of the proposed analytical framework in the previous sub-section. More specifically, for each utility-offered incentive rate, the aggregators, first, send the incentive rate signals (calculated according to Eq. (23)) to their customers; the customers then determine their best-response strategies (using Eq. (19)) and submit their optimal load reductions to their corresponding aggregators; and finally, the flexible load aggregation agents accumulate the reduced demands (using Eq. (28)) and transmit it to the MG utility. At this point, the utility calculates the operational cost of addressing power deficiencies using Eq. (1) and keeps a log of the results $\left(I_{M G O}^{*}, O C_{M G}^{*}\right)$ in case it leads to a lower operational cost as compared to the last minimum value of $O C_{M G}$ recorded. At each critical peak time-step of the day-ahead operation of the MG, the distributed algorithm is run iteratively until the constraints contained in Eqs. (15)-(17) are all relaxed and the termination condition of the algorithm is met, implying that the Nash equilibrium of the game is found. Such decentralisation of the decision-making platform ensures that all the economic actors have some clout in the game. 
Note that as proved in the previous sub-section, $O C_{M G}$ is strictly convex with respect to $I_{M G O}$; hence, search space enumeration is guaranteed to find the optimum incentive price to be offered by the utility to the aggregators, $I_{M G O}^{*}$, and, accordingly, Algorithm 1 is guaranteed to converge to the unique Nash equilibrium solution set of the devised game $\left(I_{M G O}^{*}, I_{L A}^{j, *}, d^{k, j, *}\right)$.

Algorithm 1. Proposed distributed algorithm to find the unique Nash equilibrium of the developed game.

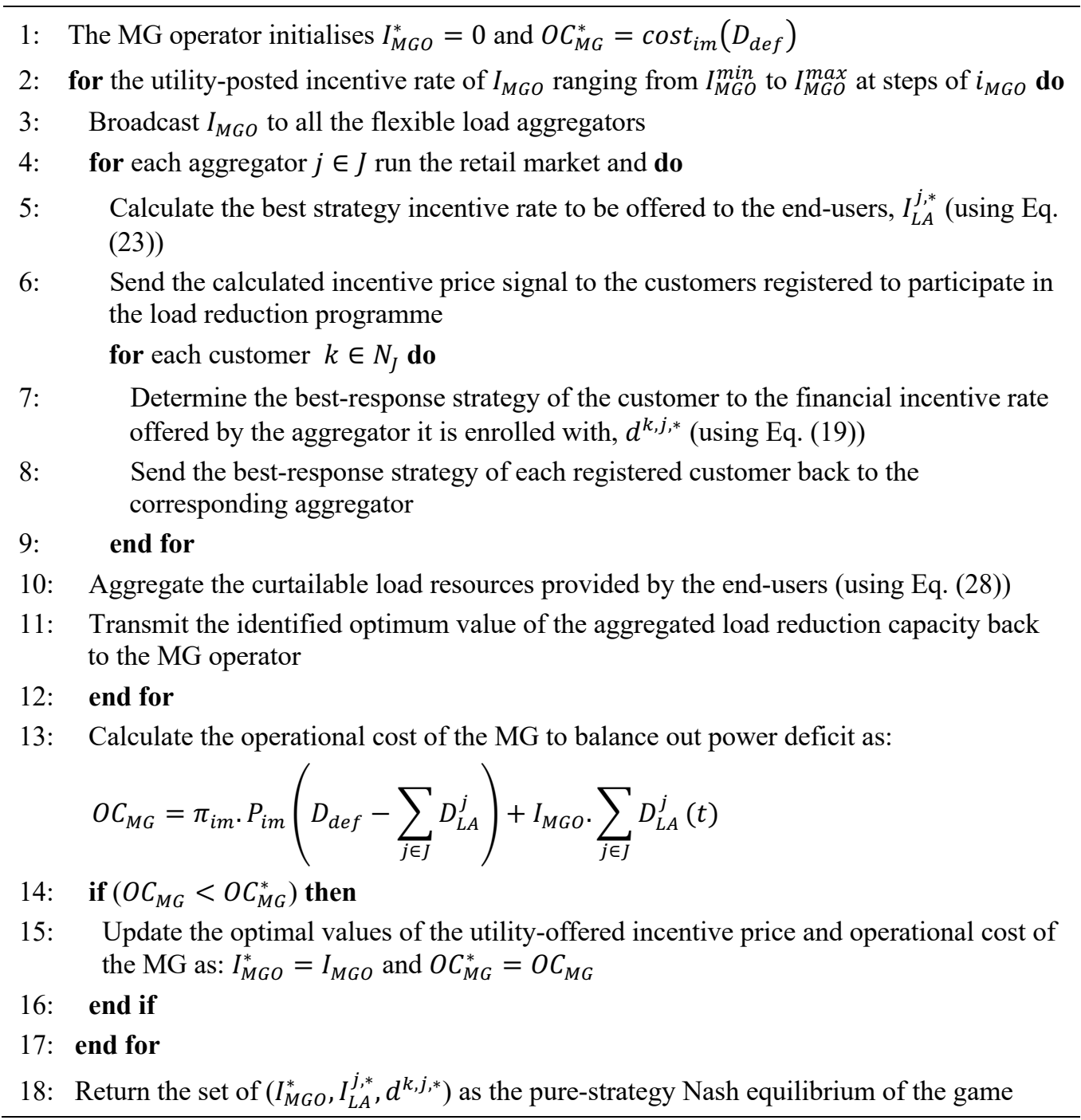

\subsubsection{Sequence of operations}

Fig. 5 presents a sequence diagram of the proposed dual-loop, market-driven, incentive-based, aggregator mediated DR scheduling framework that uses the developed privacy-preserving distributed algorithm to yield the pure-strategy Nash equilibrium of the game. As the figure shows, first, the MG system operator requests the forecasted power output from renewable power generation assets from the MG asset manager. It then sends a signal to the DRAs that announces a DR event and triggers the proposed dual-loop DSM market framework to optimally schedule the power imports and system-level dispatch of DR resources. The dual-loop DSM market design is then run iteratively at increasing values of the utility-offered incentive price for load reduction to produce an optimal trade-off between imported power and procured DR units. After determining the cost-optimal solution, the MG operator announces the cleared utility-offered incentive price to the DRAs who, in turn, announce the cleared DRA-offered incentive price to their customers. This process is repeated for each critical peak time-step of the next day. Specifically, the critical peak time-steps are considered to be the time-steps of MG operation for which a net energy deficit (positive net load) is predicted, based on the next day's total load and onsite renewable power generation forecasts. 
As the above discussion suggests, the end-consumers and, in turn, the DRAs, only disclose the information that is really required by the MG operator to be able to find an optimal DR allocation. That is, the developed iterative auction protocol that clears the proposed game-theoretic DSM market design is able to reduce the amount of information exchanged - and all associated complexities - to the essential minimum, thus preserving the privacy of the players' valuations. Indeed, the suggested iterative auctions are modelled by considering the DRAs and end-consumers as "black-boxes" that are represented by oracles, where the MG operator and DRAs repeatedly query these oracles, respectively. These oracles are shown to be incentive-compatible in sub-section 4.2, meaning that the design of the market is consistent with the factors that motivate the DRAs and end-consumers to truthfully participate in the DSM market.

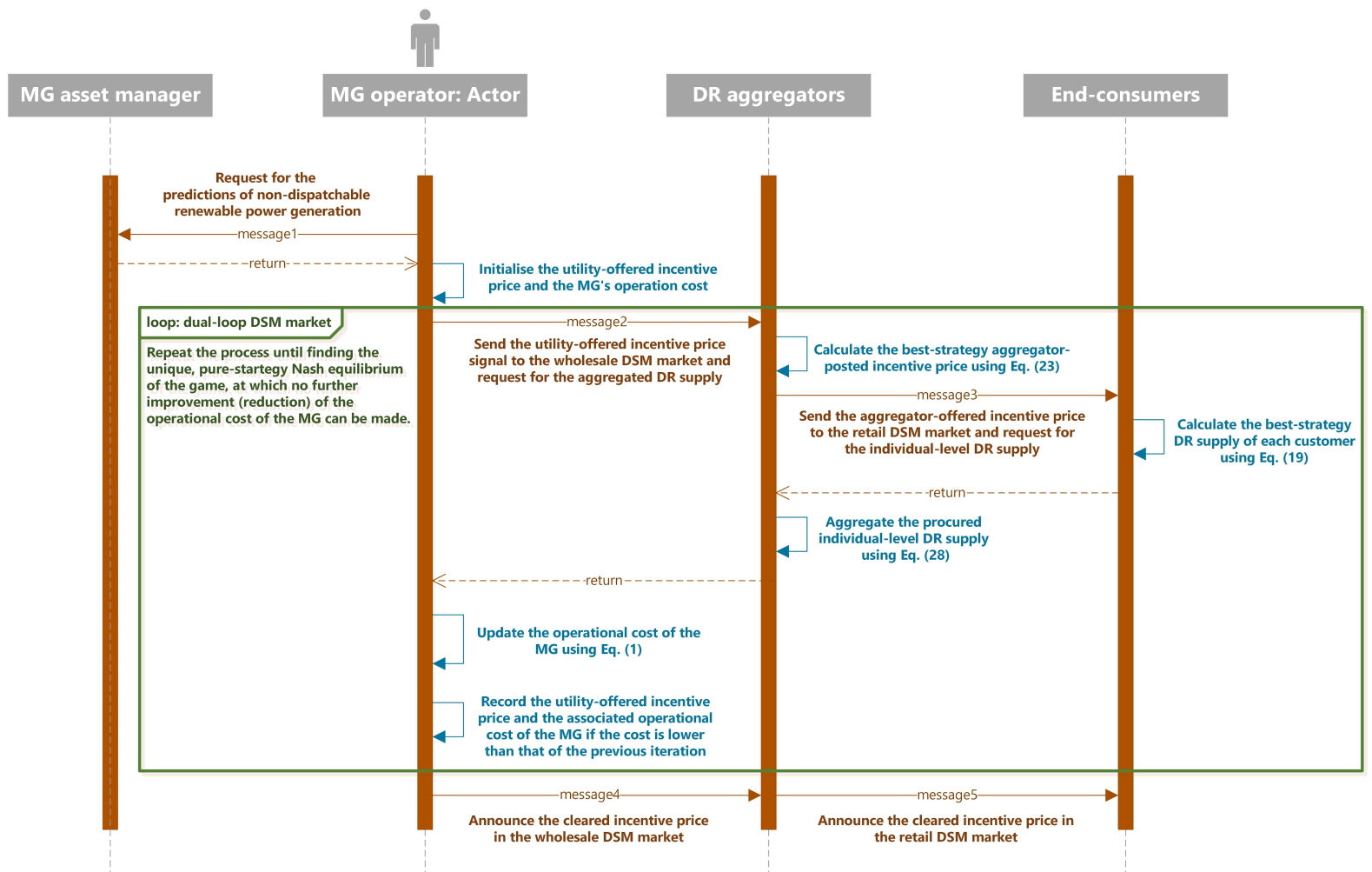

Fig. 5. Sequence diagram of the suggested distributed algorithm to solve the non-cooperative game of utilityaggregator-customer interactions in the delivery of smaller DR products.

\section{Case study: Ohakune, New Zealand}

To demonstrate the effectiveness of the proposed non-cooperative game-theoretic approach to dispatching DR resources, a case study is carried out for the town of Ohakune, in New Zealand (latitude $39.4180^{\circ} \mathrm{S}$, longitude $\left.175.3985^{\circ} \mathrm{E}\right)$. Located in the central part of the North Island of New Zealand, Ohakune is known as the 'snow season' capital of the North Island. Accordingly, the electrical load on the town's distribution system is subject to a considerable degree of seasonality. The case study is run for a representative day ( $24 \mathrm{~h}$ at hourly intervals) of the winter and summer seasons, where the one-day total energy consumption is assumed to be highest and lowest, respectively. ${ }^{2}$ Note that demand for electricity in the town of Ohakune peaks in winter with the highest daily electricity consumption occurring during the evening peak period, between 5 p.m. to 10 p.m. [68].

\subsection{Micro-grid configuration and business model}

A DC-linked, grid-tied MG system is modelled in accordance with Fig. 6, which is equipped with solar photovoltaic (PV), wind turbine (WT), and run-of-the-river micro-hydro (MH) power plants. It is assumed that the customers' overall goal is to become only partially energy resilient, where the MG is able to provide a seamless transition to critical loads during outages. To this end, given that adding storage resources carries substantial additional capital investment to the $100 \%$-renewable project [69], which is not necessary to meet the site's energy

\footnotetext{
${ }^{2}$ For the purposes of this study, winter is defined between the $1^{\text {st }}$ of June and the $31^{\text {st }}$ of August, while summer is defined between the $1^{\text {st }}$ of December and the $28^{\text {th }} / 29^{\text {th }}$ of February.
} 
resilience goals, any storage devices were excluded from the technology portfolio. Accordingly, any net energy deficits during normal grid-connected operations need to be addressed by an optimal combination of imported power and curtailed load. Such an optimal trade-off solution at critical peak time-steps can be produced by applying the proposed game-theoretic DR-integrated energy management framework.

The grid-connected community MG, which is set to reduce the cost of energy and provide more reliable energy from RESs, is assumed to be financed by the energy-as-a-service (EaaS) business model. The EaaS business model provides a flexible ownership platform, which allows end-consumers, utilities, and other financing partners to strategically collaborate and capitalise on the system [70]. However, it was decided to make a simplification of the single ownership structure, where a third party (an energy service company) - with enough experience, knowledge and financial resources - designs, builds, operates, owns, and maintains the renewables-based MG to serve different electrical load classes and charges a fee in exchange for its service. The energy tariffs are assumed to be fixed and not reflective of wholesale electricity prices. However, the end-consumers are offered financial incentives for reducing their energy use during the critical peak time-steps - where the net load on the MG is positive and wholesale prices are high - in accordance with the proposed dual-loop aggregator-mediated DSM market design. It is also assumed that the optimum size of the MG equipment is available from prior technoeconomic feasibility and optimal capacity-planning studies.

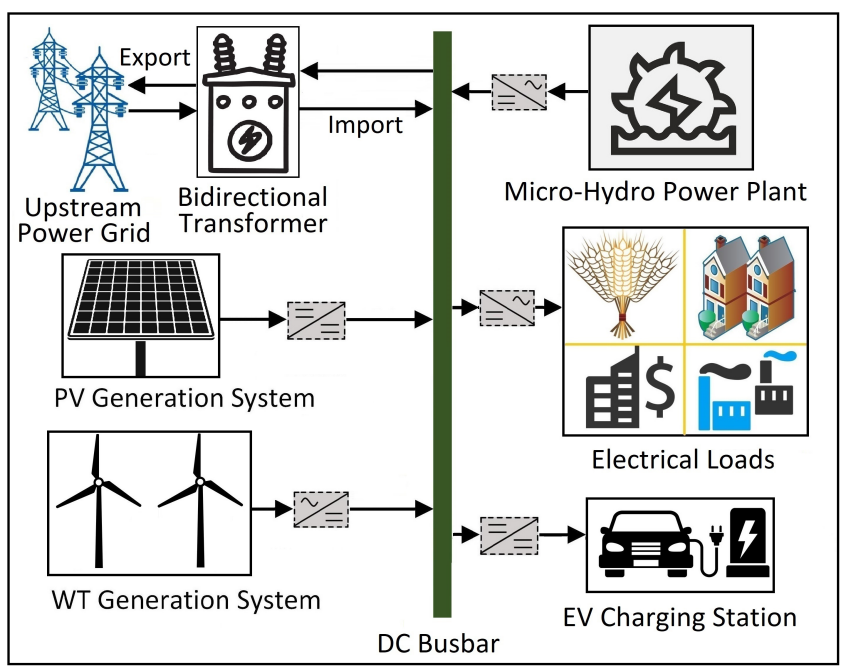

Fig. 6. Schematic of DC-linked community PV-WT-MH MG system, feeding residential, commercial, industrial, agricultural, and EV-charging loads.

\subsection{Input data}

This sub-section presents the input data supplied to the model. Table 1 presents the data values for the proposed non-cooperative game-theoretic DSM model scalars, namely: the step size of the iterative distributed algorithm, as well as the minimum and maximum bounds for the utility- and aggregator-offered incentive prices and the inconveniences experienced by the users.

Table 1. Data values and the proposed game-theoretic DSM model scalars.

\begin{tabular}{cccc}
\hline Parameter & Value & Parameter & Value \\
\hline$i_{M G O}$ & $\$ 0.020 / \mathrm{kWh}$ & $I_{L A}^{j, \max }$ & $\$ 0.300 / \mathrm{kWh}$ \\
$I_{M G O}^{\min }$ & $\$ 0.020 / \mathrm{kWh}$ & $d i s^{k, j, m i n}$ & $\$ 0.001 / \mathrm{kWh}$ \\
$I_{M G O}^{\max }$ & $\$ 0.320 / \mathrm{kWh}$ & $d i s^{k, j, m a x}$ & $\$ 0.280 / \mathrm{kWh}$ \\
$I_{L A}^{j, \min }$ & $\$ 0.010 / \mathrm{kWh}$ & & \\
\hline
\end{tabular}

\subsubsection{Load demand data}

It is assumed that the total sectoral demand forecasts are available for each hourly time-step of the next day. To forecast the total sectoral loads on the MG (excluding the EV-charging demand) over a representative day $(24 \mathrm{~h})$ of the winter and summer seasons, first, mean yearly peak load demand was determined based on the historical 
demand data [68]. The forecasted total peak demand was then broken down by the residential, commercial, industrial, and agricultural sectors in accordance with the New Zealand's Ministry of Business, Innovation and Employment's (MBIE's) most recent energy statistics [71]. Then, the forecasted residential peak demand was used to derive daily residential load profiles based on the findings of the New Zealand GREEN Grid residential electricity demand study for the representative summer and winter days with lowest and highest one-day total demands, respectively [72]. Also, the season-wise typical daily consumption patterns of electricity in Ohakune, derived from real demand profiles (from substations), were used to shape the daily load profiles of the commercial, agricultural, and industrial sectors [68].

To derive the e-mobility load profile, the EU-funded Green eMotion project dataset [73] was used as a proxy for New Zealand uptake. Accordingly, the real-driving energy consumption of a typical A-segment, small-sized EV was considered to be $257 \mathrm{Wh} / \mathrm{km}$, while accounting for the fact that the median winter energy consumption per $\mathrm{km}$ is higher than the median summer consumption by $40 \%$. The scaled e-mobility energy consumption data were then put into a New Zealand context in accordance with the estimated total energy consumption and typical daily consumption pattern of a fleet of 45 Nissan Leafs monitored by the Flip the Fleet project in New Zealand [74]. Moreover, the amount of driving done per driver was assumed to be $29 \mathrm{~km} /$ day, in compliance with New Zealand's household travel survey [75]. Fig. 7 shows the hourly total load demand on the MG for the two representative days of the summer and winter seasons.

(a)

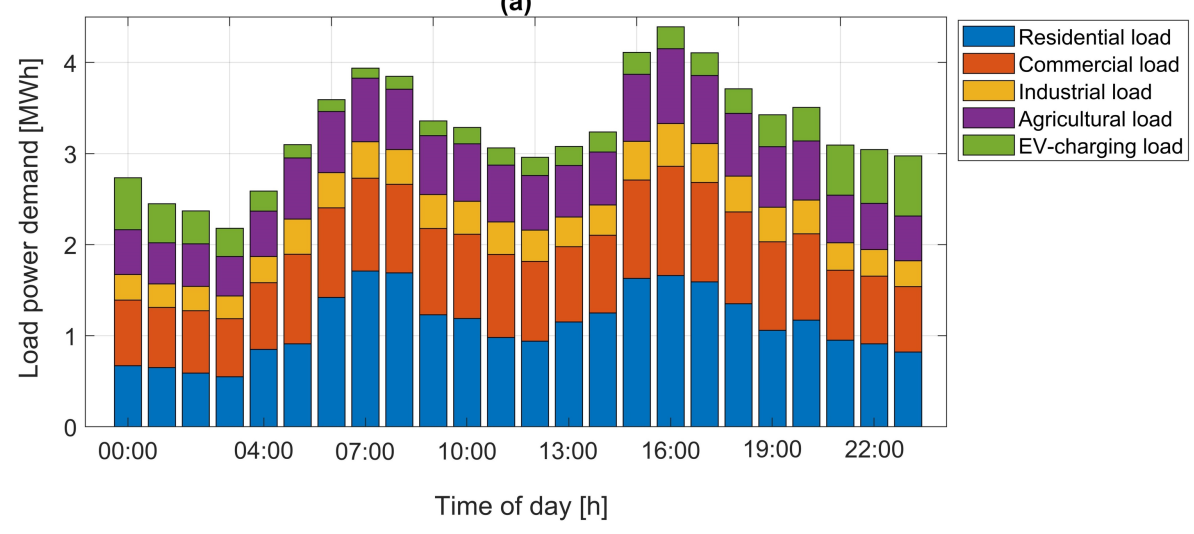

(b)

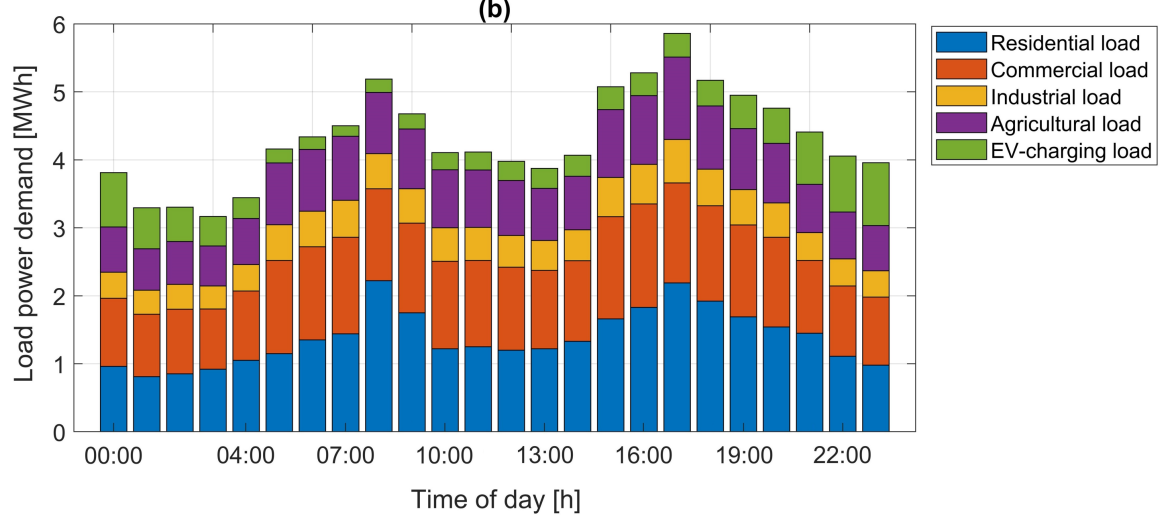

Fig. 7. Forecasted hourly total load power demand on the Ohakune's distribution system for a representative day of: (a) summer; and (b) winter.

This study is based on a synthesised district of 250 detached houses, a total of 65 small-to-medium commercial buildings, a total of 10 medium-scale industrial facilities, a total of 55 large-scale irrigation systems, as well as a fleet of $180 \mathrm{EVs}$ - to transition the town's light vehicle fleet to low-emissions. ${ }^{3}$ Accordingly, the forecasted sectorwise total load demands are disaggregated into individual customers. To this end, the DR capacity of the electrical

\footnotetext{
${ }^{3}$ For the sake of simplification, the entire EV-charging load demand is assumed to be served through the dedicated EV charging station.
} 
loads are specifically parametrised by $\delta_{j}, c_{1}^{k, j}, c_{2}^{k, j}, d_{\text {full }}^{k, j}, d_{n c r}^{k, j}, \operatorname{Par}_{\text {max }}^{j}, N_{\text {cust }}^{j}$ and the disaggregation algorithm presented in sub-section 2.2.1.3 is employed.

Data values for load type-specific and individual-level load demand parameters mentioned above were not readily available and had to be estimated based on the corresponding information available. The values of $\delta_{j}$ for residential, commercial, industrial, and agricultural loads were set according to the mean of the corresponding values of lost load in a New Zealand context [76], while for the EV-charging loads, it was set based on the mean of the values of lost load for a fleet of plug-in EVs reported in [77]. The range of values the parameters $c_{1}^{k, j}$ and $c_{2}^{k, j}$ can take were chosen based on the values reported in [41], [42] for different load types, which were normalised to the load type-dependent DR procurement factors $\left(\delta_{j}\right)$ in an inversely proportional manner. Furthermore, in view of the lack of reliable data for a New Zealand context, relevant data for eleven large U.S. utilities [78] were adopted to adjust the values of $\operatorname{Par}_{\max }^{j}$ for residential, commercial, industrial, and agricultural loads, while the value of this parameter was taken from [79] for EV-charging loads. Table 2 lists data values and sources for the proposed game-theoretic DR scheduling model parameters.

Table 2. Data values and assumption sources for the DR capacity of different customer classes.

\begin{tabular}{ccccccc}
\hline Parameter & & \multicolumn{5}{c}{ Aggregator } \\
\cline { 3 - 6 } & & Residential & Commercial & Industrial & Agricultural & EV-charging \\
\hline$\delta_{j}$ & Value & 0.48 & 0.51 & 0.57 & 0.63 & 0.76 \\
& Source & {$[76]$} & {$[76]$} & {$[76]$} & {$[76]$} & {$[77]$} \\
$c_{1}^{k, j}$ & Range & {$\left[1.08 \times 10^{-3}\right.$,} & {$\left[1.04 \times 10^{-3}\right.$,} & {$\left[0.99 \times 10^{-3}\right.$,} & {$\left[0.95 \times 10^{-3}\right.$,} & {$\left[0.91 \times 10^{-3}\right.$,} \\
& & $\left.1.15 \times 10^{-3}\right]$ & $\left.1.07 \times 10^{-3}\right]$ & $\left.1.03 \times 10^{-3}\right]$ & $\left.0.98 \times 10^{-3}\right]$ & $\left.0.94 \times 10^{-3}\right]$ \\
& Source & {$[41],[42]$} & {$[41],[42]$} & {$[41],[42]$} & {$[41],[42]$} & {$[41],[42]$} \\
$c_{2}^{k, j}$ & Range & {$\left[11.49 \times 10^{-3}\right.$,} & {$\left[11.31 \times 10^{-3}\right.$,} & {$\left[11.71 \times 10^{-3}\right.$,} & {$\left[11.25 \times 10^{-3}\right.$,} & {$\left[11.40 \times 10^{-3}\right.$,} \\
& & $\left.11.70 \times 10^{-3}\right]$ & $\left.11.48 \times 10^{-3}\right]$ & $\left.11.86 \times 10^{-3}\right]$ & $\left.11.30 \times 10^{-3}\right]$ & $\left.11.57 \times 10^{-3}\right]$ \\
& Source & {$[41],[42]$} & {$[41],[42]$} & {$[41],[42]$} & {$[41],[42]$} & {$[41],[42]$} \\
$d_{f u l l}^{k, j}$ & Range & {$[8,30]$} & {$[20,100]$} & {$[100,200]$} & {$[30,65]$} & {$[5,30]$} \\
{$[\mathrm{kW}]$} & Source & $($ this paper) & (this paper) & $($ this paper) & $($ this paper) & (this paper) \\
$d_{\text {ncr }}^{k, j}$ & Range & {$[2.5,16.5]$} & {$[5,60]$} & {$[20,84]$} & {$[10,46.2]$} & {$[4,25.5]$} \\
{$[\mathrm{kW}]$} & Source & $($ this paper) & (this paper) & (this paper) & (this paper) & (this paper) \\
Par max $_{\text {max }}^{j, j}$ & Value & 55 & 60 & 42 & 71 & 85 \\
{$[\%]$} & Source & {$[78]$} & {$[78]$} & {$[78]$} & {$[78]$} & {$[79]$} \\
$N_{\text {cust }}^{j}$ & Value(s) & 250 & 65 & 10 & 55 & 180 \\
& Source & (this paper) & (this paper) & (this paper) & (this paper) & (this paper) \\
\hline
\end{tabular}

\subsubsection{Onsite generation data}

The optimum size of the solar PV, WT, and MH power plants were respectively assumed to be $1 \mathrm{MW}, 6 \mathrm{MW}$, and 1.2 MW. To estimate the power output from these power plants for each hour of the representative days, first, the hourly solar irradiance, ambient temperature, wind speed, and river streamflow data were forecasted using the NIWA $^{4}$ National Climate Database (CliFlo) [80]. To this end, the rolling average of solar irradiance, ambient temperature, wind speed, and river streamflow were calculated for each hour of the historical days on which the lowest and highest one-day total demands were occurred (over a 20-year period, between 1999 and 2018). The power outputs from the solar PV, WT, and MH generation systems were then determined based on the forecasted meteorological data using the formulas given in [81]. Fig. 8 displays the forecasted power outputs from the PV, WT, and MH power plants for the representative days of the summer and winter seasons.

\footnotetext{
${ }^{4}$ New Zealand's National Institute of Water and Atmospheric Research.
} 


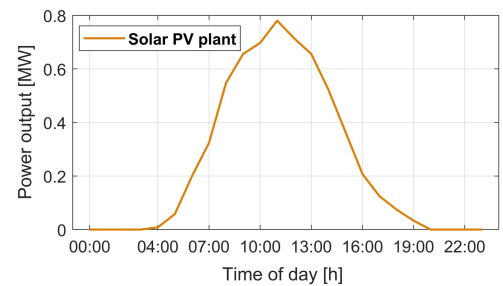

Time of day [h]

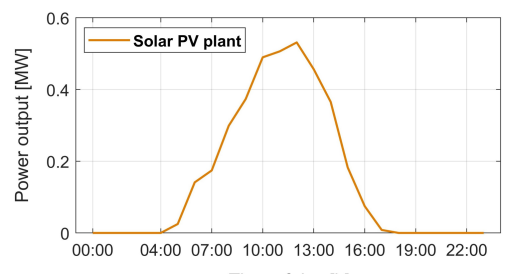

Time of day [h]

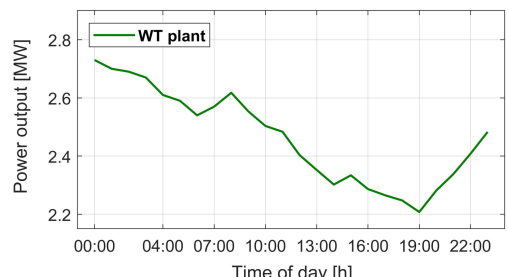

Time of day [h]

(b)

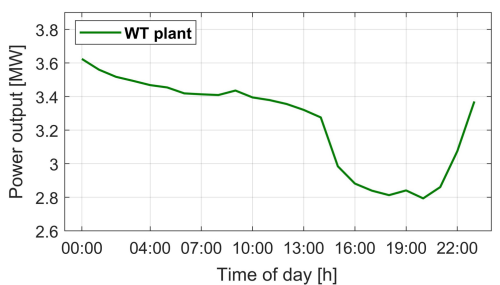

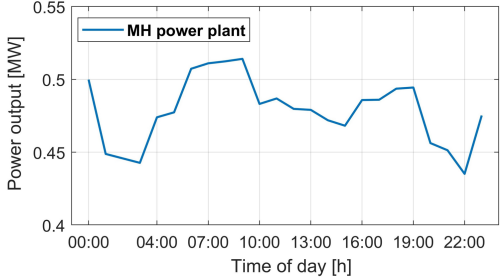

Time of day [h]

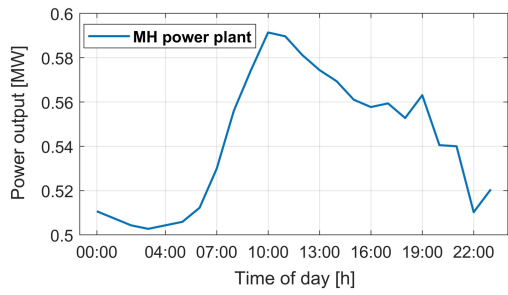

Fig. 8. Power outputs from the PV, WT, and MH power plants for a representative day of: (a) summer; and (b) winter.

\subsubsection{Wholesale electricity price data}

Wholesale electricity market prices are provided in Fig. 9. The figure presents the rolling average of the electricity price for each hour of the historical days on which the lowest and highest one-day total demands were recorded, during the timeframe of 2008 to 2019 . To this end, historical nodal electricity price data at the Ohakune's grid exit point were retrieved from the New Zealand's electricity market database [82]. Note that although wholesale electricity prices are high during the morning peak hours of the representative days, higher levels of total power generation from onsite DERs - and, particularly, WTs - offset, to a considerable extent, the need to implement a DR programme during these hours. Also note that given that hydropower is the dominant source of power generation in New Zealand's energy mix, spot electricity prices are higher during the summer season in most regions of New Zealand, including Ohakune. ${ }^{5}$
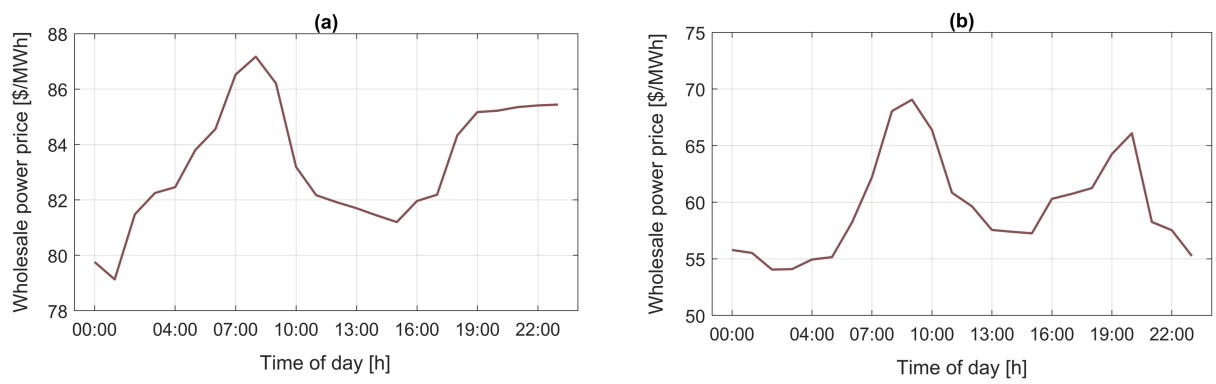

Fig. 9. Forecasted nodal wholesale electricity price data at the Ohakune's grid exit point for a representative day of: (a) summer; and (b) winter.

\section{Results and discussion}

The results obtained by applying the proposed modelling framework to the test-case, laid out in Section 3, are analysed and validated in this section through scenario testing. To validate the feasibility and utility of the proposed dual-loop, Stackelberg, strategic game-theoretic DR scheduling framework in identifying the best compromise between the imported power and utilised DR capacity on the day-ahead timeframe, two scenarios are tested, with the typical summer and winter days discussed in Section 3. More specifically, the input data to the proposed model, namely the day-ahead meteorological, wholesale electricity price, and load demand data profiles, as well as the parameter settings associated with different customer classes, are the same as those presented in Section 3. Subsequently, the discomfort costs and revenues for end-consumers, the profits for the DRAs, and the utility for the MG operator are presented and analysed for the two scenarios. Specifically, the efficacy of the

\footnotetext{
${ }^{5}$ The reason for this is the more reliance on thermal electricity generation and natural gas-fired 'peaker' power plants during the dryer season.
} 
proposed distributed algorithm to determine the unique, pure-strategy Nash equilibrium of the aggregatormediated DSM game is verified in sub-section 4.1; a financial balance assessment of the devised game structure is conducted in sub-section 4.2; and the incentive compatibility ${ }^{6}$ of the proposed DR scheduling design is demonstrated in sub-section 4.3. The code was developed and run in MATLAB (version 9.5, R2018b) [83].

\subsection{Scenario analysis}

The proposed game-theoretic DR scheduling framework is applied on a day-ahead basis and relies on the forecasts of non-dispatchable renewables, wholesale prices, and load demand, based on which financial incentives are posted to the wholesale DSM market by the MG operator for load reduction. Accordingly, to facilitate understanding of the model behaviour, the process of procuring DR provisions is illustrated by two typical scenarios for representative days of the summer and winter seasons, where the MG loading levels are lowest and highest, respectively. This is mainly because low-temperature heat is the main $(\sim 63 \%)$ use of household energy in New Zealand, providing space heat $(\sim 34 \%)$ and water heat ( 29\%) [84].

The convergence process of the proposed iterative distributed algorithm (described in sub-section 2.2.4) to the unique, pure-strategy Nash equilibrium of the devised DSM game is depicted in Fig. 10 for the hours of the two representative summer and winter days at which DR resources are elicited. Also, the contribution of load power demand reduction and imported electricity from the main grid at the hours of these two days where there is a shortfall in onsite power generation capacity to meet the load on the MG is detailed in Fig. 11. The figure also shows the sector-wise unreleased DR capacity to suggest the validity of the model results in terms of producing optimal trade-offs between importing electricity and harnessing the capacity of DR resources, whilst adhering to the quality of service desired by different customer classes. As can be seen in the figure, the highest daily rate of DR execution on the selected typical summer and winter days is expected to occur at 5 p.m. and 6 p.m., respectively, which can be characterised as the "daily most critical peak hour". Moreover, to provide a more indepth understanding of the iterative incentive coordination mechanism, a breakdown of the optimised operational cost of the MG at the most critical peak hour of each representative day - to offset the anticipated power supply deficit (refer to Eq. (1)) - into incentive payments and cost of purchasing power from the main grid against various rates of utility-provided financial incentives, is summarised in Fig. 12. Furthermore, a closed-form solution of the optimal incentive rate from the utility's perspective for the two daily most critical peak hours under discussion can be obtained using Eq. (32). Accordingly, the analytically calculated optimal incentive rates offered by the utility to the load aggregators at the considered hours are presented in Fig. 13.

(a)
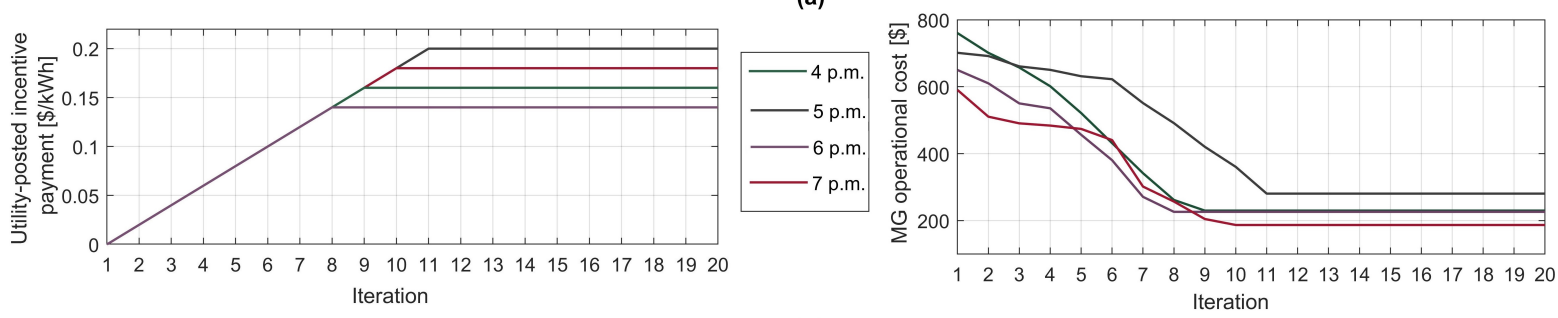

(b)
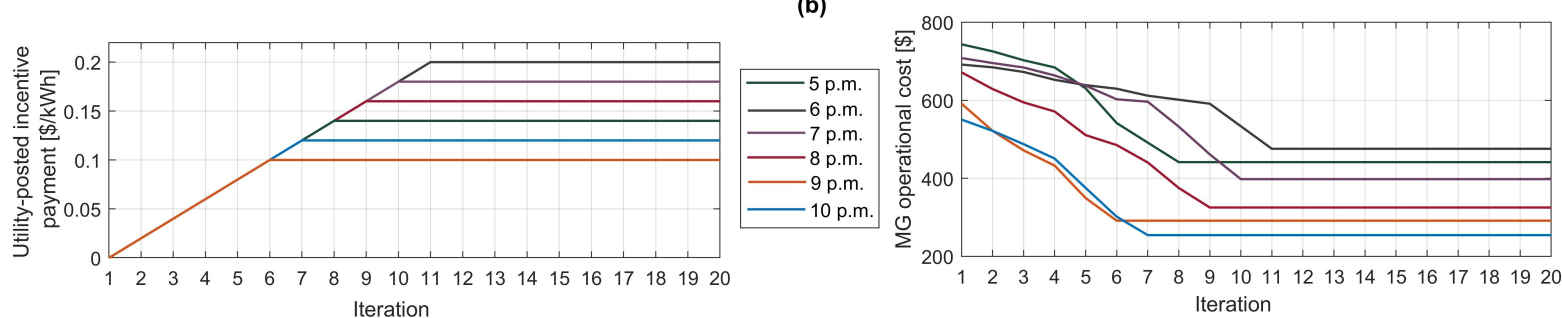

Fig. 10. Convergence process of the distributed algorithm developed to determine the unique, pure-strategy Nash equilibrium of the proposed game-theoretic DR framework on the representative days: (a) summer day; and (b) winter day.

\footnotetext{
${ }^{6}$ Put simply, a mechanism is said to be incentive-compatible (truthfully implementable) in the context of mechanism design, if every player can attain the best outcome possible by behaving in accordance with their true preferences [15].
} 
(a)

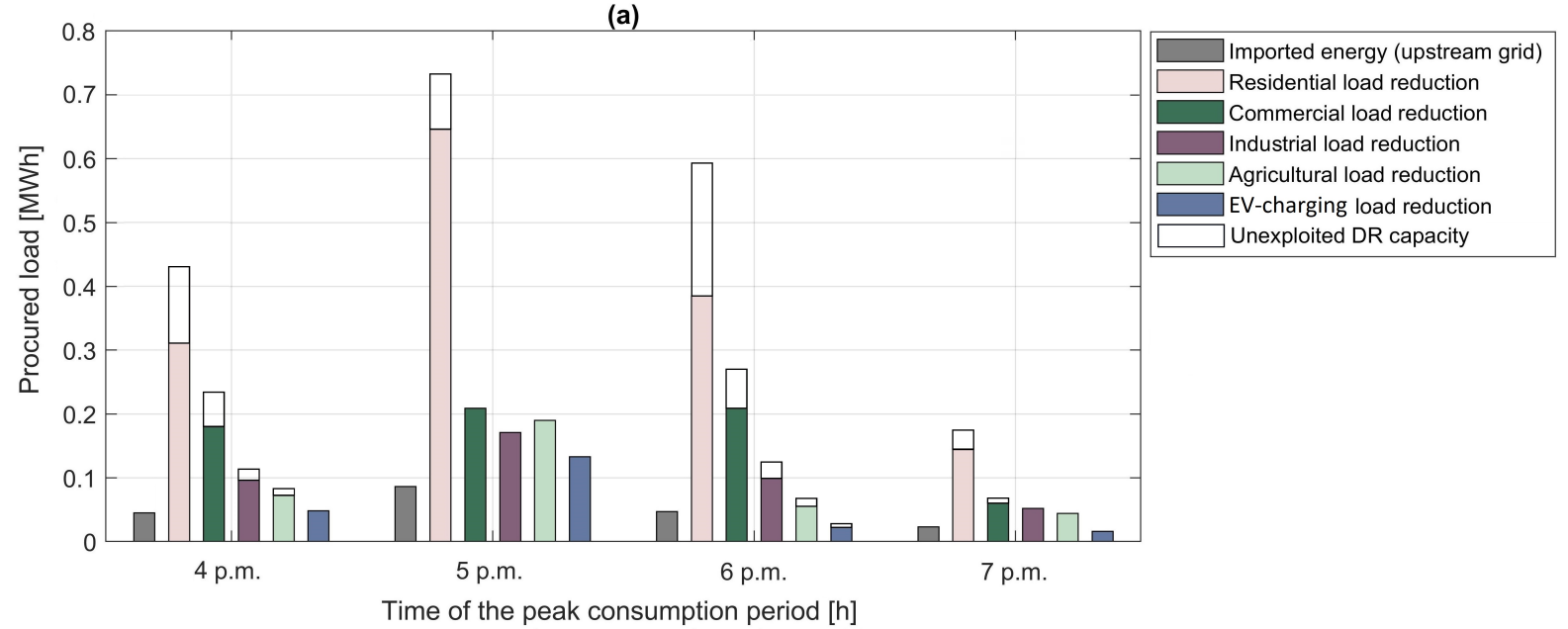

(b)

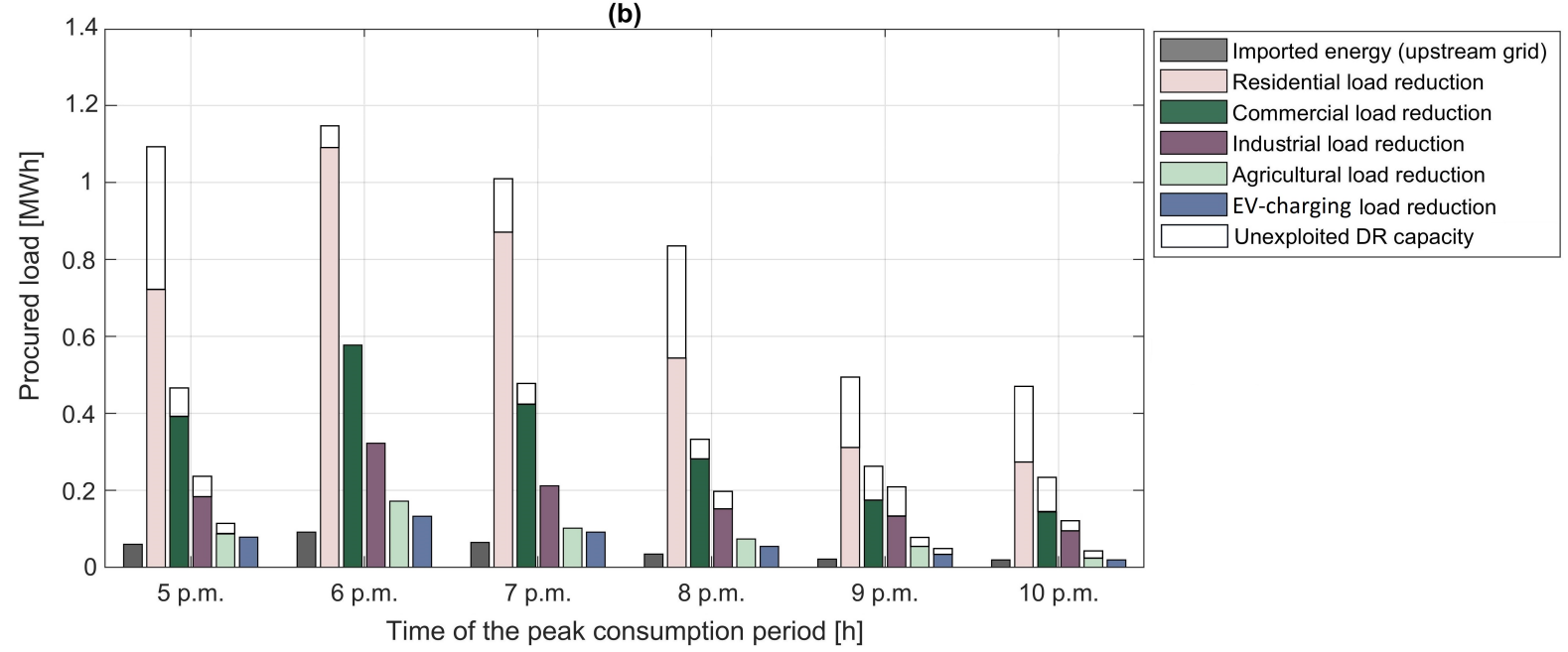

Fig. 11. Breakdown of the contribution of demand reduction and imported electricity from the main grid in the face of onsite generation capacity deficits on the representative days: (a) summer day; and (b) winter day. Note the change in scale in the dependent axes. 
(a)
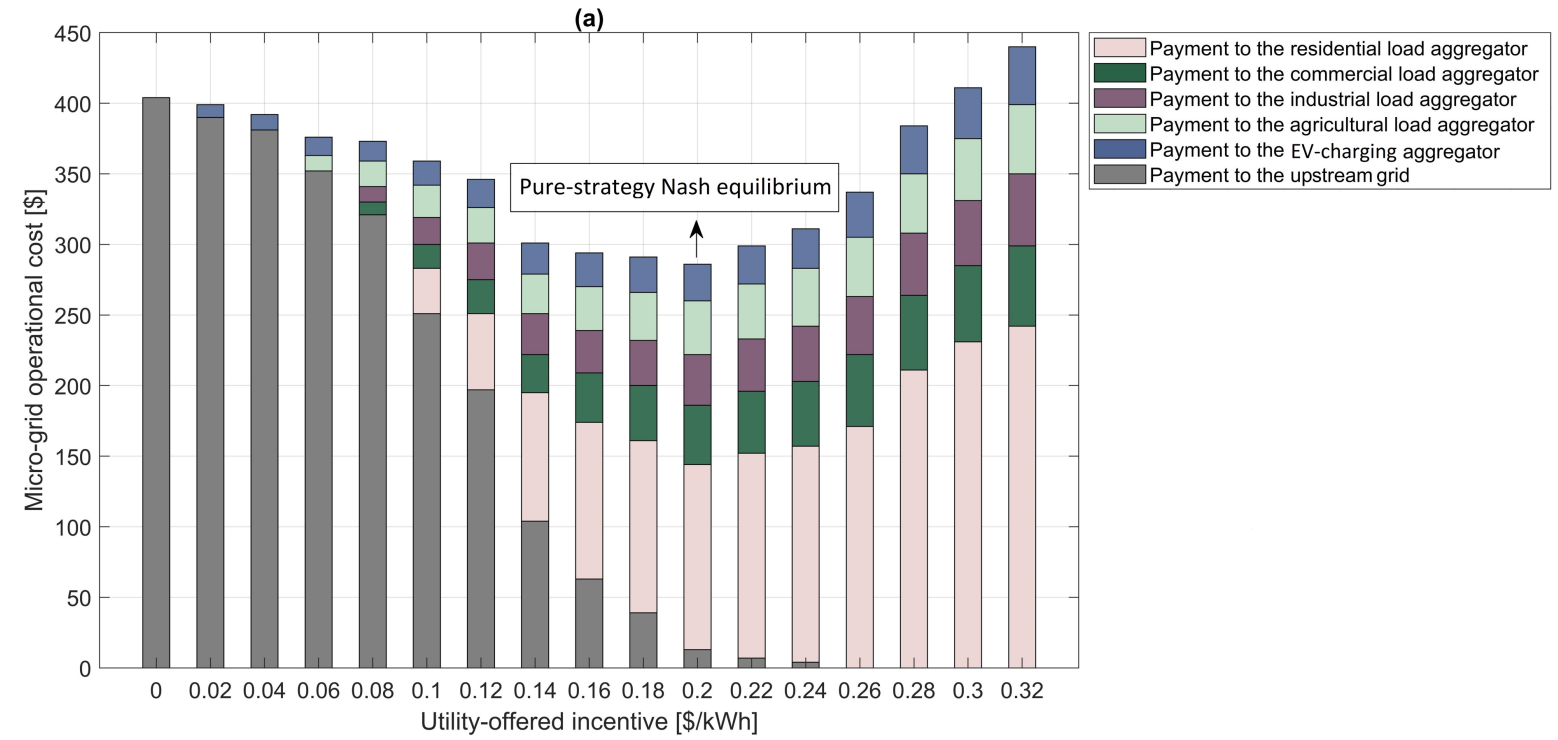

Payment to the upstream grid
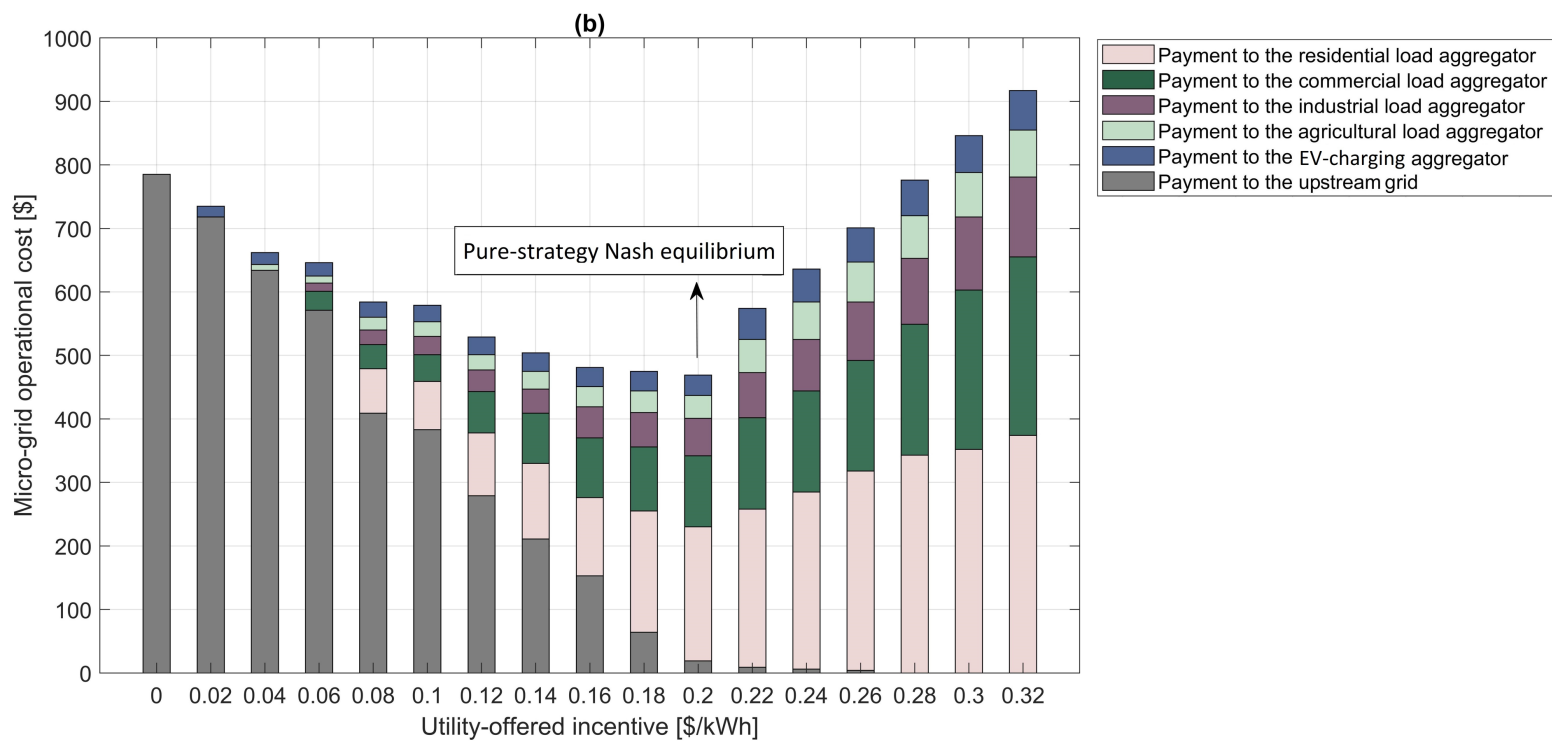

Fig. 12. Breakdown of the minimised day-ahead operational cost of the MG with respect to different utilityposted incentive rates at the most critical peak hour of the representative days: (a) 5 p.m. summer day; and (b) 6 p.m. winter day. Note the change in scale in the dependent axes.

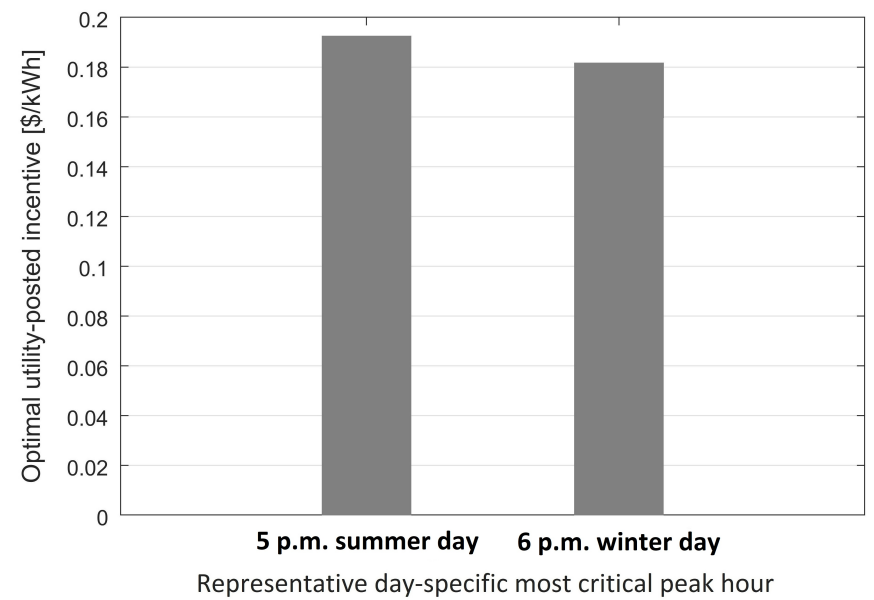

Fig. 13. Closed-form solution of the optimal utility-posted incentive rate at the two representative daily most critical peak time-steps. 
Several key implications can be derived from the results presented in Figs. 10-13:

1. The proposed dual-loop, Stackelberg, strategic game-theoretic framework can be viewed as a two-sided, zero-sum game with complete but imperfect information, ${ }^{7}$ which delivers tangible economic benefits to all the active economic agents involved in the game, namely: the utility, responsive load aggregators, and end-consumers. More specifically, the aggregate MG operational cost during the critical peak hours of the typical summer and winter days is reduced to $\$ 911.66(\sim 66 \%)$ and $\$ 2,124.16(\sim 47 \%)$, from $2,692.25 \$$ and $\$ 4,039.30$, respectively, compared to the case with no DR procurements; determined in the first iteration of the distributed algorithm (see Fig. 10).

2. The results presented in Fig. 12 indicate that there exists a knee point on the curve fitted to the hourly day-ahead operational costs of the system to address onsite generation capacity deficits. The more the solution deviates from this knee point (from either side), the worse the cost solution. However, a comparison of the impacts of the rightward and leftward deviations from the unique, pure-strategy Nash equilibrium of the game suggests that the overpayment to the aggregators has a more negative impact on the optimal trade-off cost solution than under-exploiting the DR resources. Also note that the abovementioned knee point is driven by the total amount of DR resources available, and the overall discomfort characteristics of the customers.

3. A one-by-one comparison of the analytically-determined (closed-form), optimal utility-offered incentive prices with those obtained by the proposed distributed algorithm shows a discrepancy of less than $\$ 0.02 / \mathrm{kWh}$, which equals the step size used to update the utility-offered financial incentives $\left(i_{M G O}\right)$. Not only does this corroborate the validity and usefulness of the distributed algorithm, but it also indicates that the accuracy of the proposed distributed algorithm depends primarily on the selected step size.

\subsection{Incentive flow analysis}

This sub-section aims to provide details on the financial balance of the proposed incentive-directed, noncooperative game-theoretic DR management framework through illustrative examples. To this end, the hours at which the highest levels of DR resources were elicited in the two typical daily scenarios concerned, namely 5 p.m. summer day and 6 p.m. winter day, were selected for a comprehensive financial incentive flow analysis. Accordingly, Table 3 details the flow of financial incentives, from the utility to the aggregators and then to the end-consumers, together with their associated levels of demand reduction and discomfort cost. Note that all the information is extracted from the pure-strategy Nash equilibrium obtained by the proposed distributed algorithm.

Table 3. Detailed results of the inflow and outflow of financial incentives for the two illustrative time-steps: 5 p.m. summer day and 6 p.m. winter day.

\begin{tabular}{|c|c|c|c|c|}
\hline \multirow[t]{2}{*}{ Player category } & \multirow[t]{2}{*}{ Variable } & \multirow[t]{2}{*}{ Energy-use sector ${ }^{*}$} & \multicolumn{2}{|c|}{ Scenario } \\
\hline & & & 5 p.m. summer day & 6 p.m. winter day \\
\hline \multirow[t]{2}{*}{ The utility } & $\begin{array}{c}\text { Total incentive } \\
\text { payment of the utility } \\
\text { to the aggregators [\$] }\end{array}$ & - & 271.8 & 459.1 \\
\hline & $\begin{array}{l}\text { Total load reduction } \\
\text { expected by the } \\
\text { utility }[\mathrm{kWh}]\end{array}$ & - & $1,358.8$ & $2,295.7$ \\
\hline \multirow{10}{*}{$\begin{array}{c}\text { Demand response } \\
\text { aggregators }\end{array}$} & \multirow{5}{*}{$\begin{array}{l}\text { Total incentive } \\
\text { payment of the } \\
\text { aggregator to its } \\
\text { customers [\$] }\end{array}$} & $\mathrm{R}$ & 55.6 & 88.5 \\
\hline & & $\mathrm{C}$ & 16.6 & 42.7 \\
\hline & & I & 15.5 & 18.7 \\
\hline & & A & 14.1 & 11.3 \\
\hline & & $\mathrm{E}$ & 8.9 & 7.7 \\
\hline & \multirow{5}{*}{$\begin{array}{l}\text { Total profit gained by } \\
\text { the aggregator }[\$]\end{array}$} & $\mathrm{R}$ & 75.3 & 129.9 \\
\hline & & $\mathrm{C}$ & 24.4 & 72.7 \\
\hline & & I & 20.9 & 45.8 \\
\hline & & A & 25.0 & 23.0 \\
\hline & & E & 15.5 & 18.8 \\
\hline
\end{tabular}

\footnotetext{
${ }^{7}$ This assumes that each player knows who the other players are and what their strategy sets are, but does not generally know the exact form of the objective function they are trying to optimise - and thus how they will react in different situations.
} 

Total load reduction
procured by the
aggregator $[\mathrm{kWh}]$

End-consumers ${ }^{\dagger}$

\author{
Total utility of the \\ customers [\$]
}

Total discomfort cost of the customers [\$]

\section{$\mathrm{R}$}

654.5

205.0

$1,092.0$

C

181.9

577.1

I

195.6

322.5

A

E

121.9

171.6

132.4

R

26.7

42.6

C

8.5

8.2

8.9

$\begin{array}{lll}\text { E } & 6.8 & 6.0\end{array}$

21.7

9.9

7.1

$\begin{array}{lll}\text { E } & 6.8 & 6.0\end{array}$

$\begin{array}{lll}\mathrm{R} & 28.9 & 45.9\end{array}$

$\begin{array}{lll}\text { C } & 8.1 & 20.9\end{array}$

$\begin{array}{lll}\text { I } & 7.3 & 8.8\end{array}$

$\begin{array}{lll}\text { A } & 5.2 & 4.2\end{array}$

E 2.1

"The letters 'R', 'C', 'I', 'A', and 'E' respectively stand for 'Residential', 'Commercial, 'Industrial', 'Agricultural', and 'E-mobility'.

$\dagger$ Given the high number of customers considered in the case study (see Table 2), the reader is referred to Supplementary Material accompanying the paper (Additional File 1: Optimal demand response provision by customer) for a detailed breakdown of the customers' individual incentive income, utility, discomfort cost, and contribution to load reduction.

From Table 3, the following observations can be made for both the daily most critical peak time-steps analyses:

1. According to the top-level transactions processed in the wholesale DSM market, the total incentives paid by the utility equals the sum of the financial incentives received by the aggregators. ${ }^{8}$ Accordingly, the total load reduction expected by the utility equals the aggregated load reduction packages delivered by the aggregators.

2. Based on the bottom-level transactions made in the retail DSM market, the sum of the total utility of each category of end-consumers - generated by delivering their DR resources - and the total discomfort cost imposed on them, equals the total incentive payment made by their respective aggregator. Accordingly, the sum of load reductions contributed by each aggregator's customers equals the respective aggregator's contribution to the overall load reduction consistent with its commitment in the wholesale DSM market.

The observations discussed above collectively confirm the balance of incentive inflows and outflows over the considered time-steps from the perspective of all the players of the game.

Moreover, the per-unit profits obtained by load aggregators - defined as a ratio of total profit gained by each aggregator to the total load reduction it has procured at a given time-step $[\$ / \mathrm{kWh}]$ - by acting as energy brokers in the wholesale DSM market and, at the same time, leading the retail DSM market, indicate that the utility of a DRA is roughly correlated with the overall willingness of its consumers to participate in the DR programmes. The uniform incentive price settlement design considered in the two-stage DSM market is the underlying reason for this.

\subsection{Incentive compatibility assessment}

To verify that the proposed game-theoretic DSM approach is incentive-compatible (truthfully implementable) from the utility's perspective, the consequences of the aggregators' and end-consumers' deviations from their best strategies are explored in this sub-section. To this end, the most critical peak hours of the representative days are again studied. The profits gained by the aggregators are calculated with respect to various levels of financial incentives offered to their customers, which are shown in Fig. 14. Also, the results of the sensitivity analysis of the utility of a randomly-selected end-consumer, from each category of loads, to variations in its load reduction supply capacity, are shown in Fig. 15. The values of the representative customers' discomfort-related coefficients and DR capacities, as well as detailed results of the inflow and outflow of incentives for the two indicative timesteps, are highlighted in grey in Supplementary Material accompanying the paper (Additional File 1: Optimal demand response provision by customer).

\footnotetext{
${ }^{8}$ Note that according to Eq. (5), the amount of financial incentive received by each DRA equals the sum of the profit it earns by playing the role of DR broker and the total amount of financial incentives it pays to its participating customers.
} 
(a)

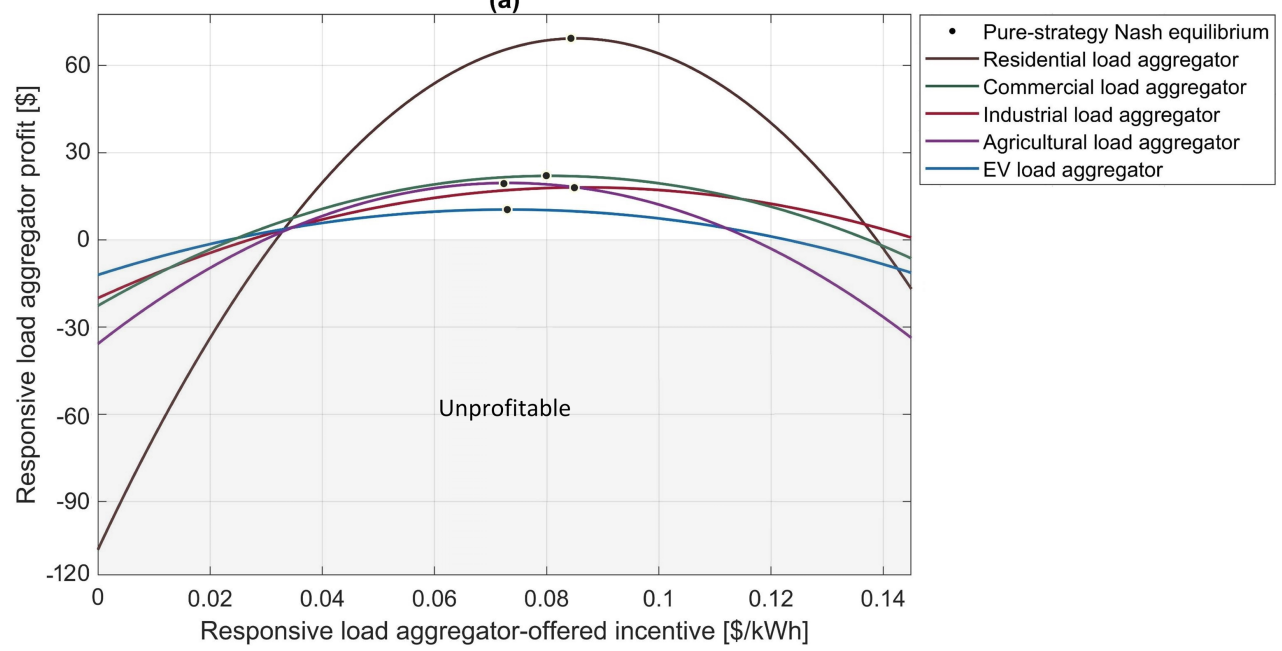

(b)

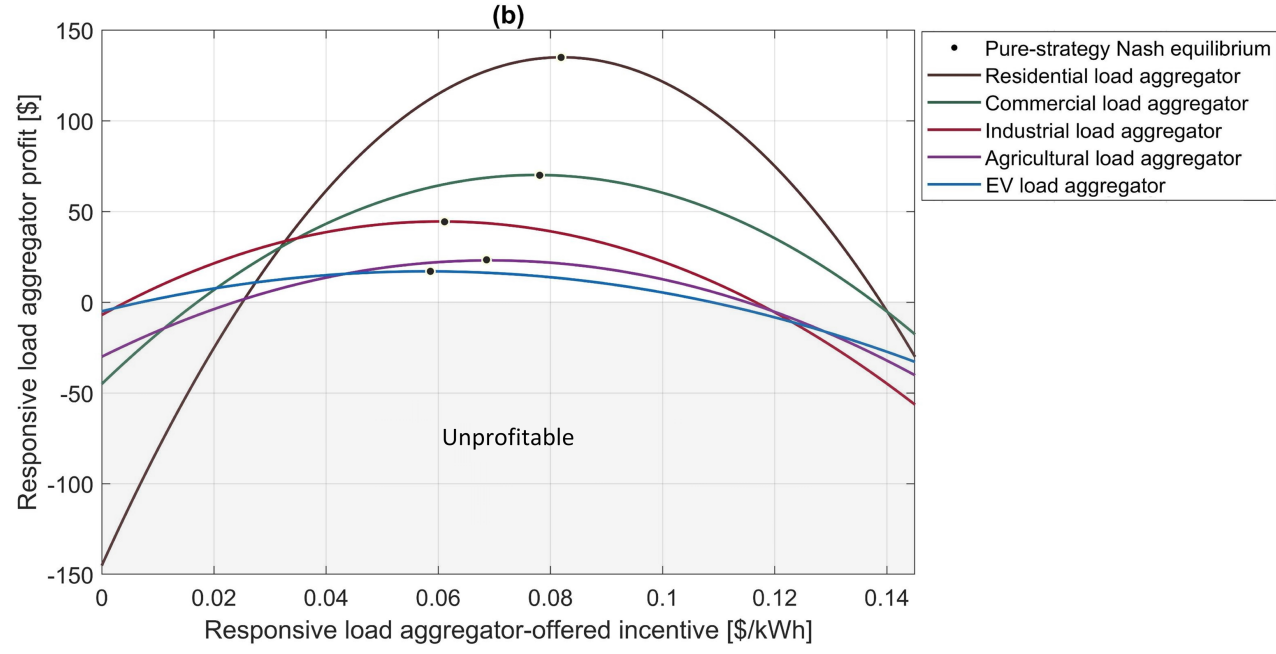

Fig. 14. Sensitivity of the aggregators' profits to variations in their incentive payment rates to end-consumers at the most critical peak hour of the representative days: (a) 5 p.m. summer day; and (b) 6 p.m. winter day. Note the change in scale in the dependent axes.

(a)
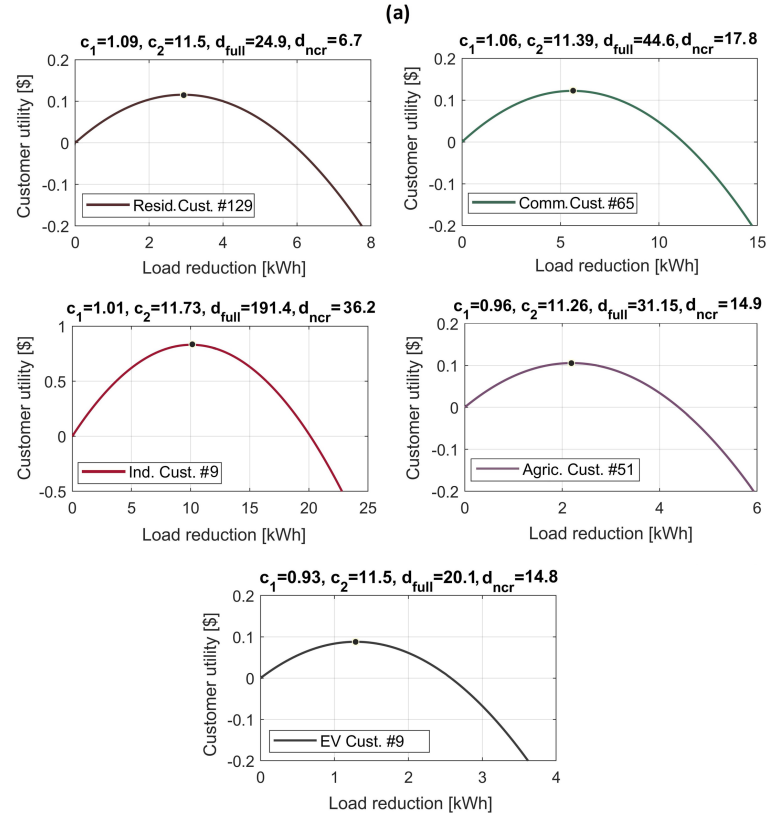

(b)
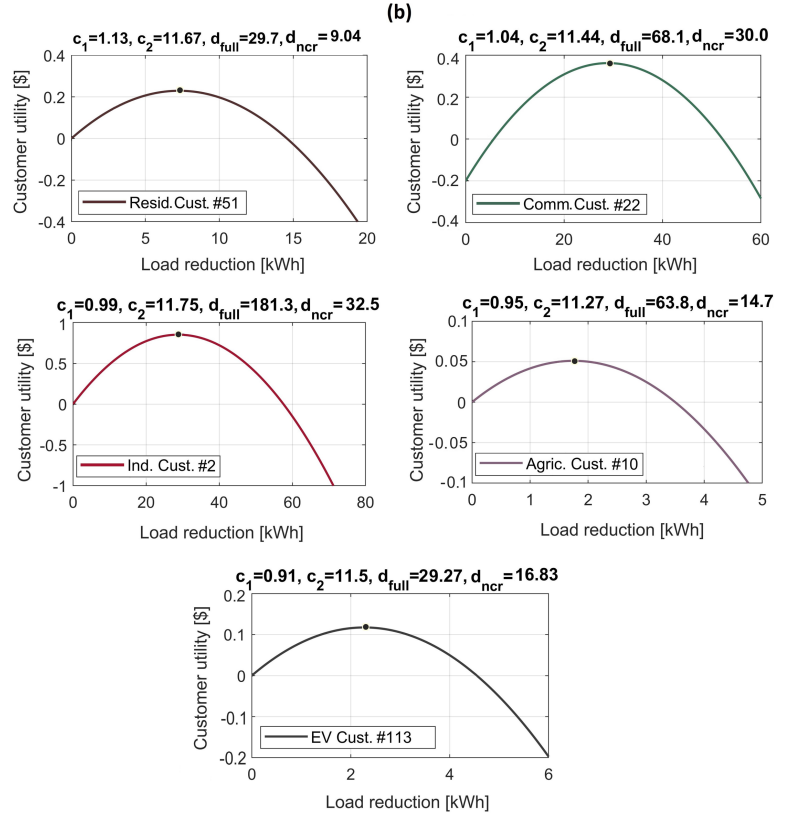
Fig. 15. Sensitivity of the utility of a representative customer of each aggregator to variations in its load reduction supply capacity at the most critical peak hour of the representative days: (a) 5 p.m. summer day; and

(b) 6 p.m. winter day. Note the change in scale in the dependent and independent axes.

As shown in Fig. 14, any deviation of the aggregators from their best strategies at the Nash equilibrium point leads to a reduction in their profits; thus, none of the aggregators have any useful deviations. It should be noted that each aggregator's profit can be expressed as a second-order polynomial function of the incentive rate it offers, by substituting the best-response strategies of its customers into its profit function (refer to Eq. (21)). The rationale behind this quadratic polynomial equation for an aggregator's profit is straightforward. For any utility-posted incentive rate, increasing the aggregator-offered incentive rate increases customer engagement, which improves the aggregator's profit. However, at a certain point - vertex of the associated parabola - this effect levels off and increasing the aggregator-offered incentive rate begins to show a reverse effect in which the gains from increased participation tends to drive the aggregator's profit down - where the aggregator's marginal revenue falls below its marginal cost - as a result of dealing with less-elastic customers and/or overcompensation of DR suppliers in the retail DSM market.

Also, the prime reason why the optimal aggregator-offered incentive rate varies across different customer classes is that the model accommodates detailed customisation for the sector- and customer-specific DR supply elasticity (refer to Table 2), which generally assumes that the supply of DR capacity is more responsive for EV-charging customers, as well as for industrial and agricultural customers, than for residential and commercial customers.

Furthermore, a comparison of the aggregators' profit profiles for the considered two extreme time-steps, from Fig. 14 , reveals that each aggregator's best-response incentive price strategy also varies over the course of time. To illustrate, while the best-response strategy of the aggregators for the time-step 6 p.m. winter day, shown in Fig. 14(b), seems to be in inverse proportion to the DR supply elasticity of the considered customer sectors, no specific trend can be discerned for the relationship between the best-response strategy of the aggregators and the sectoral DR supply elasticity for the time-step 5 p.m. summer day, depicted in Fig. 14(a). The latter observation indicates the possibility of the involvement of additional factors in determining the aggregators' best strategies, such as the stochasticity inherent in the employed load demand disaggregation algorithm and the randomness associated with the number of EVs that plug-in and initiate a standard charging event at each time-step, which remain to be characterised. In addition, the difference in the profit levels of different aggregators can be principally explained by the share of each sector in the total energy demand and its respective DR supply capacity. In this light, a key insight from Fig. 14 is that while the aggregators' payoff varies as a function of the utility demand for DR capacity and the sector-wide share in the total energy consumption, the rank order of their profitability is subject to instability throughout time - excluding the residential and EV aggregators that most and least benefitted from economies of scale, respectively. Such instability results largely from the sector-specific seasonal and diurnal variations in load demand. Additionally, some of the aforementioned rank order instability may be attributed to the same sources of uncertainty as noted for the variability of each aggregator's optimal incentive rate.

Moreover, as demonstrated in Fig. 15, none of the representative customers has an incentive to deviate from its best-response strategy, as it results in reducing the utility it derives from load reduction. Recall that the customer discomfort cost, the lower and upper bounds of which are adjusted, is a function of the reduced load by the customer (see Eq. (11)), according to which the maximum load reduction that can be procured by each customer can be calculated.

As demonstrated above, in either case, the proposed game-theoretic DR scheduling framework leads to truthrevealing and deviation-proof solutions - in that there is no deviation by load aggregators or end-consumers. Moreover, the evidence from these analyses points towards the idea that the obtained optimal solution can be regarded as the fully-revealing rational expectations equilibrium of the game - in that none of the game's players would change their actions even if they were aware of the outcomes of the game.

It should also be emphasised that the sensitivity of the aggregators' profits to variations in their posted incentive rate, and the sensitivity of the customers' utilities to variations in their supplied load reduction, are mainly dictated by the adjusted values for the willingness of different load classes to engage in DR programmes.

\section{Conclusions and future work}

Small- to medium-scale end-users are opening up new opportunities for RSESs to accommodate high penetrations of non-dispatchable renewable electricity generation in terms of flexibility. Accordingly, DRAs are emerging in response to this trend, acting as intermediary between these smaller energy users and grid operators to unlock the potential of retail demand-side flexibility resources - and develop competitive, efficient, and reliable interruptible DR services at scale. This study designed the first price elasticity-aware, market-driven, incentive-based, aggregator-mediated DR scheduling model tailored to grid-connected RSESs. The model successfully generalised 
the Stackelberg, non-cooperative game-theoretic, aggregator-mediated DR planning problem in the following three areas:

1. The model quantified the optimal trade-off between electricity importing costs and incentive payments made to the DRAs by including the cost of importing electricity (as a function of the wholesale electricity price) and the cost of procuring DR flexibility products in the utility's operational cost (payoff) function.

2. The model incorporated the estimated elasticity of supply of DR capacity in different end-use sectors residential, commercial, industrial, agricultural, and electrified transport - to improve the quality and accuracy of short-term forecasts on the participation rate of different customer classes. This enabled the model to identify the more profitable DRAs in a uniform price settlement system.

3. The model included a large number of end-users in each sector, which allowed the analysis of a broad spectrum of strategy profiles and the corresponding payoffs in different end-use sectors. To this end, a stochastic total sectoral load disaggregation technique was employed, which had real-world implications for the pre-feasibility techno-economic assessment of RSESs.

The paper analytically demonstrates the existence and uniqueness of a pure-strategy Nash equilibrium for the formulated aggregator-mediated, Stackelberg, non-cooperative game-theoretic DSM problem. It also develops a specific distributed algorithm to approximate the unique, pure-strategy Nash equilibrium point of the game based on the endogenous Stackelberg leader-follower relationship. The proposed distributed algorithm used an indirect way of sending information about the players' valuation, namely an iterative auction. Notably, on both the wholesale and retail levels, the DSM auction protocol iteratively interacted with different DR providers and endconsumers, eliciting sufficient information about their preferences to determine the optimal allocation of DR units. This adaptive process provides a platform to preserve the privacy of the DRAs and end-consumers. The distributed algorithm was also shown to perform well in converging to the approximate Nash equilibrium of the devised game, with the algorithm precision controlled by the iteration step length.

A number of novel insights emerged from the modelling results of the numerical test-case MG of the town of Ohakune, in New Zealand:

1. Producing the optimal trade-off between importing power and exploiting the flexibility potential of smaller DR products for the critical peak hours of system operation - for which a net energy deficit is predicted - is able to reduce the daily system operational cost by $\sim 66 \%$ (equating to a saving of $\$ 912$ ) and $\sim 47 \%$ (equating to a saving of $\$ 2,124$ ) on a representative summer and winter day, respectively.

2. There is a saturation point for the use of DR resources, which varies with respect to the wholesale electricity price. The more the optimal trade-off cost solution deviates from this saturation point, the worse the hourly operational cost solution. Specifically, overpayment for DR products more negatively affects the trade-off operational cost solution than underutilisation of flexible DR resources.

3. Likewise to the optimal utility-offered incentive price, the best-response-strategy aggregator-posted incentive price is time-step-specific, which occurs at different prices across different aggregators. Accordingly, the hourly rank order of the profitability of different aggregator classes varies mainly as a function of the share of each end-use sector in the total procured DR capacity, while the best-response aggregator-determined incentive rate varies with respect to the sectoral and customer-specific (individual-level) discomfort cost parameters (that define their strategic behaviours), in addition to the utility-posted incentive price in the wholesale DSM market.

Future work could seek to improve the proposed model by including group strategy-proof mechanisms to ensure that both the wholesale and retail DSM markets are arbitrage-free and collusion-resistant, whilst additionally supporting a Pareto optimal and economically efficient allocation of demand-side resources. Another area for future research is to examine whether a discriminatory (pay-as-bid) design would be a superior strategy to the uniform price design strategy in terms of the optimal social welfare or, more specifically, to quantify the impact of the inframarginal DR capacity on the level of market-clearing prices - which can add an additional layer of insight into the specific characteristics of the aggregator-mediated DSM markets.

\section{References}

[1] International Renewable Energy Agency (IRENA). Electrification with renewables - Driving the transformation of energy services. 2019. Available: https://www.irena.org//media/Files/IRENA/Agency/Publication/2019/Jan/IRENA_RE- 
Electrification_SGCC_2019_preview.pdf [Accessed: 4-Aug.-2020].

[2] C. Li, Y. Yao, R. Zhao, and K. Xie, "Optimization model for time-varying settlement of renewable energy consumption considering accommodation difficulty and supply-demand interaction," Int. J. Electr. Power Energy Syst., vol. 125, p. 106469, 2021, doi: https://doi.org/10.1016/j.ijepes.2020.106469.

[3] H. Dorotić, B. Doračić, V. Dobravec, T. Pukšec, G. Krajačić, and N. Duić, "Integration of transport and energy sectors in island communities with $100 \%$ intermittent renewable energy sources," Renew. Sustain. Energy Rev., vol. 99, pp. 109-124, 2019, doi: https://doi.org/10.1016/j.rser.2018.09.033.

[4] B. Zhou, Y. Meng, W. Huang, H. Wang, L. Deng, S. Huang, and J. Wei, "Multi-energy net load forecasting for integrated local energy systems with heterogeneous prosumers," Int. J. Electr. Power Energy Syst., vol. 126, Part A, p. 106542, 2021, doi: https://doi.org/10.1016/j.ijepes.2020.106542.

[5] C. Dortans, M. W. Jack, B. Anderson, and J. Stephenson, "Lightening the load: quantifying the potential for energy-efficient lighting to reduce peaks in electricity demand," Energy Effic., 2020, doi: 10.1007/s12053-020-09870-8

[6] M. Ahmadi, O. B. Adewuyi, M. S. S. Danish, P. Mandal, A. Yona, and T. Senjyu, "Optimum coordination of centralized and distributed renewable power generation incorporating battery storage system into the electric distribution network," Int. J. Electr. Power Energy Syst., vol. 125, p. 106458, 2021, doi: https://doi.org/10.1016/j.ijepes.2020.106458.

[7] A. O. Abbas and B. H. Chowdhury, "Using customer-side resources for market-based transmission and distribution level grid services - A review," Int. J. Electr. Power Energy Syst., vol. 125, p. 106480, 2021, doi: https://doi.org/10.1016/j.ijepes.2020.106480.

[8] W. Huang, N. Zhang, C. Kang, M. Li, and M. Huo, "From demand response to integrated demand response: review and prospect of research and application," Prot. Control Mod. Power Syst., vol. 4, no. 1, p. 12, 2019, doi: 10.1186/s41601-019-0126-4.

[9] E. Koliou, C. Eid, J. P. Chaves-Ávila, and R. A. Hakvoort, "Demand response in liberalized electricity markets: Analysis of aggregated load participation in the German balancing mechanism," Energy, vol. 71, pp. 245-254, 2014, doi: https://doi.org/10.1016/j.energy.2014.04.067.

[10] A. Obermeier, C. Windmeier, E. Esche, and J.-U. Repke, "A Discrete-time Scheduling Model for Continuous Power-intensive Processes Considering Fatigue of Equipment," in 28 European Symposium on Computer Aided Process Engineering, vol. 43, A. Friedl, J. J. Klemeš, S. Radl, P. S. Varbanov, and T. B. T.-C. A. C. E. Wallek, Eds. Elsevier, 2018, pp. 955-960.

[11] S. Abapour, B. Mohammadi-Ivatloo, and M. Tarafdar Hagh, "Robust bidding strategy for demand response aggregators in electricity market based on game theory," J. Clean. Prod., vol. 243, p. 118393, 2020, doi: https://doi.org/10.1016/j.jclepro.2019.118393.

[12] Y. Chen, W. S. Lin, F. Han, Y.-H. Yang, Z. Safar, and K. J. R. Liu, "Incentive compatible demand response games for distributed load prediction in smart grids," APSIPA Trans. Signal Inf. Process., vol. 3, 2014, doi: https://doi.org/10.1017/ATSIP.2014.8.

[13] U.S. Department of Energy. Benefits of Demand Response in Electricity Markets and Recommendations for Achieving Them - A report to the United States congress pursuant to Section 1252 of the Energy Policy Act 2005. 2006. Available: https://eetd.lbl.gov/sites/all/files/publications/report-lbnl-1252d.pdf [Accessed: 4-Aug.-2020].

[14] A. C. Chapman, G. Verbič, and D. J. Hill, "A healthy dose of reality for game-theoretic approaches to residential demand response," in 2013 IREP Symposium Bulk Power System Dynamics and Control-IX Optimization, Security and Control of the Emerging Power Grid, Rethymno, Greece, 25-30 Aug. 2013, pp. 1-13, doi: https://doi.org/10.1109/AUPEC.2018.8757882.

[15] T. Roughgarden, "Algorithmic game theory," Commun. ACM, vol. 53, no. 7, pp. 78-86, 2010, doi: https://doi.org/10.1145/1785414.1785439.

[16] N. Nisan and A. Ronen, "Algorithmic mechanism design," Games Econ. Behav., vol. 35, no. 1-2, pp. 166-196, 2001, doi: https://doi.org/10.1006/game.1999.0790.

[17] M. O. Jackson, "Mechanism theory," Available SSRN 2542983, 2014, doi: https://dx.doi.org/10.2139/ssrn.2542983. 
[18] Edison Electric Institute. Power Market Auction Design: Rules and Lessons In Market-based Control for the New Electricity Industry. 2001. Available:

http://web.mit.edu/esd.126/www/MktsAuctions/EEI.pdf [Accessed: 4-Aug.-2020].

[19] R. Amir and I. Grilo, "Stackelberg versus Cournot equilibrium," Games Econ. Behav., vol. 26, no. 1, pp. 1-21, 1999, doi: https://doi.org/10.1006/game.1998.0650.

[20] J. Nash, “Non-Cooperative Games,” Ann. Math., vol. 54, no. 2, pp. 286-295, 1951, doi: $10.2307 / 1969529$.

[21] M. Yu and S. H. Hong, "Incentive-based demand response considering hierarchical electricity market: A Stackelberg game approach,” Appl. Energy, vol. 203, pp. 267-279, 2017, doi: https://doi.org/10.1016/j.apenergy.2017.06.010.

[22] J. Wang, H. Zhong, Z. Ma, Q. Xia, and C. Kang, "Review and prospect of integrated demand response in the multi-energy system," Appl. Energy, vol. 202, pp. 772-782, 2017, doi: https://doi.org/10.1016/j.apenergy.2017.05.150.

[23] F. Shariatzadeh, P. Mandal, and A. K. Srivastava, "Demand response for sustainable energy systems: A review, application and implementation strategy," Renew. Sustain. Energy Rev., vol. 45, pp. 343-350, 2015, doi: https://doi.org/10.1016/j.rser.2015.01.062.

[24] Y. Chen, P. Xu, J. Gu, F. Schmidt, and W. Li, "Measures to improve energy demand flexibility in buildings for demand response (DR): A review," Energy Build., vol. 177, pp. 125-139, 2018, doi: https://doi.org/10.1016/j.enbuild.2018.08.003.

[25] J. Von Neumann and O. Morgenstern, Theory of games and economic behavior (commemorative edition). Princeton University Press, 2007.

[26] E. Reihani, M. Motalleb, M. Thornton, and R. Ghorbani, “A novel approach using flexible scheduling and aggregation to optimize demand response in the developing interactive grid market architecture," Appl. Energy, vol. 183, pp. 445-455, 2016, doi: https://doi.org/10.1016/j.apenergy.2016.08.170.

[27] M. Motalleb and R. Ghorbani, "Non-cooperative game-theoretic model of demand response aggregator competition for selling stored energy in storage devices," Appl. Energy, vol. 202, pp. 581-596, 2017 , doi: https://doi.org/10.1016/j.apenergy.2017.05.186.

[28] M. Motalleb, A. Annaswamy, and R. Ghorbani, “A real-time demand response market through a repeated incomplete-information game," Energy, vol. 143, pp. 424-438, 2018, doi: https://doi.org/10.1016/j.energy.2017.10.129.

[29] X. Liu, D. Tang, and Z. Dai, “A Bayesian Game Approach for Demand Response Management Considering Incomplete Information,” J. Mod. Power Syst. Clean Energy, In Press, 2021, doi: https://doi.org/10.35833/MPCE.2020.000288.

[30] R. Sharifi, A. Anvari-Moghaddam, S. H. Fathi, and V. Vahidinasab, "A bi-level model for strategic bidding of a price-maker retailer with flexible demands in day-ahead electricity market," Int. J. Electr. Power Energy Syst., vol. 121, p. 106065, 2020, doi: https://doi.org/10.1016/j.ijepes.2020.106065.

[31] M. Shafiekhani, A. Badri, M. Shafie-Khah, and J. P. S. Catalão, "Strategic bidding of virtual power plant in energy markets: A bi-level multi-objective approach,” Int. J. Electr. Power Energy Syst., vol. 113, pp. 208-219, 2019, doi: https://doi.org/10.1016/j.ijepes.2019.05.023.

[32] F. H. Moghimi and T. Barforoushi, “A short-term decision-making model for a price-maker distribution company in wholesale and retail electricity markets considering demand response and real-time pricing," Int. J. Electr. Power Energy Syst., vol. 117, p. 105701, 2020, doi: https://doi.org/10.1016/j.ijepes.2019.105701.

[33] M. Rayati, M. Bozorg, A. M. Ranjbar, and R. Cherkaoui, "Balancing management of strategic aggregators using non-cooperative game theory," Electr. Power Syst. Res., vol. 184, p. 106297, 2020, doi: https://doi.org/10.1016/j.epsr.2020.106297.

[34] M. Dadashi, S. Haghifam, K. Zare, M.-R. Haghifam, and M. Abapour, "Short-term scheduling of electricity retailers in the presence of Demand Response Aggregators: A two-stage stochastic Bi-Level programming approach," Energy, vol. 205, p. 117926, 2020, doi: https://doi.org/10.1016/j.energy.2020.117926.

[35] P. Salyani, M. Abapour, and K. Zare, "Stackelberg based optimal planning of DGs and electric vehicle 
parking lot by implementing demand response program," Sustain. Cities Soc., vol. 51, p. 101743, 2019, doi: https://doi.org/10.1016/j.scs.2019.101743.

[36] E. Fernandez, M. J. Hossain, and M. S. H. Nizami, "Game-theoretic approach to demand-side energy management for a smart neighbourhood in Sydney incorporating renewable resources," Appl. Energy, vol. 232, pp. 245-257, 2018, doi: https://doi.org/10.1016/j.apenergy.2018.09.171.

[37] S. Abapour, B. Mohammadi-Ivatloo, and M. T. Hagh, "A bayesian game theoretic based bidding strategy for demand response aggregators in electricity markets," Sustain. Cities Soc., vol. 54, p. 101787, 2020, doi: https://doi.org/10.1016/j.scs.2019.101787.

[38] S. Fan, Q. Ai, and L. Piao, "Bargaining-based cooperative energy trading for distribution company and demand response," Appl. Energy, vol. 226, pp. 469-482, 2018, doi: https://doi.org/10.1016/j.apenergy.2018.05.095.

[39] Z. Song, J. Shi, S. Li, Z. Chen, W. Yang, and Z. Zhang, "Day Ahead Bidding of a Load Aggregator Considering Residential Consumers Demand Response Uncertainty Modeling," Appl. Sci., vol. 10, p. 7310, 2020, doi: https://doi.org/10.3390/app10207310.

[40] Y. Chen, M. Olama, X. Kou, K. Amasyali, J. Dong, and Y. Xue, "Distributed Solution Approach for a Stackelberg Pricing Game of Aggregated Demand Response," in 2020 IEEE Power \& Energy Society General Meeting (PESGM), Montreal, QC, Canada, 2-6 Aug. 2020, pp. 1-5.

[41] N. I. Nwulu and X. Xia, "Multi-objective dynamic economic emission dispatch of electric power generation integrated with game theory based demand response programs," Energy Convers. Manag., vol. 89, pp. 963-974, 2015, doi: https://doi.org/10.1016/j.enconman.2014.11.001.

[42] N. I. Nwulu and X. Xia, "Implementing a model predictive control strategy on the dynamic economic emission dispatch problem with game theory based demand response programs," Energy, vol. 91, pp. 404-419, 2015, doi: https://doi.org/10.1016/j.energy.2015.08.042.

[43] Z. Fan, "A distributed demand response algorithm and its application to PHEV charging in smart grids," IEEE Trans. Smart Grid, vol. 3, no. 3, pp. 1280-1290, 2012, doi: https://doi.org/10.1109/TSG.2012.2185075.

[44] B. Chai, J. Chen, Z. Yang, and Y. Zhang, "Demand Response Management With Multiple Utility Companies: A Two-Level Game Approach," IEEE Trans. Smart Grid, vol. 5, no. 2, pp. 722-731, 2014, doi: https://doi.org/10.1109/TSG.2013.2295024.

[45] R. Tang, S. Wang, and H. Li, "Game theory based interactive demand side management responding to dynamic pricing in price-based demand response of smart grids," Appl. Energy, vol. 250, pp. 118-130, 2019, doi: https://doi.org/10.1016/j.apenergy.2019.04.177.

[46] N. Guo, Y. Wang, and G. Yan, "A double-sided non-cooperative game in electricity market with demand response and parameterization of supply functions," Int. J. Electr. Power Energy Syst., vol. 126, Part A, p. 106565, 2021, doi: https://doi.org/10.1016/j.ijepes.2020.106565.

[47] N. Guo, Y. Wang, G. Yan, and J. Hou, "Non-Cooperative Game in Block Bidding Markets Considering Demand Response," Energies, vol. 13, p. 3322, 2020, doi: https://doi.org/10.3390/en13133322.

[48] H. Golmohamadi, R. Keypour, B. Bak-Jensen, and J. R. Pillai, "A multi-agent based optimization of residential and industrial demand response aggregators," Int. J. Electr. Power Energy Syst., vol. 107, pp. 472-485, 2019, doi: https://doi.org/10.1016/j.ijepes.2018.12.020.

[49] S. Pal, S. Thakur, R. Kumar, and B. K. Panigrahi, "A strategical game theoretic based demand response model for residential consumers in a fair environment," Int. J. Electr. Power Energy Syst., vol. 97, pp. 201-210, 2018, doi: https://doi.org/10.1016/j.ijepes.2017.10.036.

[50] M. Tavakkoli, S. Fattaheian-Dehkordi, M. Pourakbari-Kasmaei, M. Liski, and M. Lehtonen, "BonusBased Demand Response Using Stackelberg Game Approach for Residential End-Users Equipped With HVAC System," IEEE Trans. Sustain. Energy, vol. 12, no. 1, pp. 234-249, 2021, doi: https://doi.org/10.1109/TSTE.2020.2989583.

[51] H. Ren, A. Zhang, F. Wang, X. Yan, Y. Li, N. Duić, M. Shafie-Khah, and J. P. S. Catalão, "Optimal scheduling of an EV aggregator for demand response considering triple level benefits of three-parties," Int. J. Electr. Power Energy Syst., vol. 125, p. 106447, 2021, doi:

https://doi.org/10.1016/j.ijepes.2020.106447. 
[52] I. Şengör, A. Çiçek, A. K. Erenoğlu, O. Erdinç, and J. P. S. Catalão, "User-comfort oriented optimal bidding strategy of an electric vehicle aggregator in day-ahead and reserve markets," Int. J. Electr. Power Energy Syst., vol. 122, p. 106194, 2020, doi: https://doi.org/10.1016/j.ijepes.2020.106194.

[53] H. Zhong, L. Xie, and Q. Xia, "Coupon incentive-based demand response: Theory and case study," IEEE Trans. Power Syst., vol. 28, no. 2, pp. 1266-1276, 2012, doi: https://doi.org/10.1109/TPWRS.2012.2218665.

[54] S. O. Sobhani, S. Sheykhha, and R. Madlener, "An integrated two-level demand-side management game applied to smart energy hubs with storage," Energy, vol. 206, p. 118017, 2020, doi: https://doi.org/10.1016/j.energy.2020.118017.

[55] C. Feng, Z. Li, M. Shahidehpour, F. Wen, and Q. Li "Stackelberg game based transactive pricing for optimal demand response in power distribution systems," Int. J. Electr. Power Energy Syst., vol. 118, p. 105764, 2020, doi: https://doi.org/10.1016/j.ijepes.2019.105764.

[56] J. Vuelvas, F. Ruiz, and G. Gruosso, "Limiting gaming opportunities on incentive-based demand response programs,” Appl. Energy, vol. 225, pp. 668-681, 2018, doi: https://doi.org/10.1016/j.apenergy.2018.05.050.

[57] A. S. Gazafroudi, M. Shafie-Khah, F. Prieto-Castrillo, J. M. Corchado, and J. P. S. Catalão, "Monopolistic and Game-based Approaches to Transact Energy Flexibility," IEEE Trans. Power Syst., vol. 35, no. 2, pp. 1075-1084, 2019, doi: https://doi.org/10.1109/TPWRS.2019.2944200.

[58] Y. Li, C. Wang, G. Li, and C. Chen, "Optimal scheduling of integrated demand response-enabled integrated energy systems with uncertain renewable generations: A Stackelberg game approach," Energy Convers. Manag., vol. 235, p. 113996, 2021, doi: https://doi.org/10.1016/j.enconman.2021.113996.

[59] T. Başar and G. J. Olsder, Dynamic noncooperative game theory ( $2^{\text {nd }}$ edition). Society for Industrial and Applied Mathematics, Philadelphia, PA, 1998.

[60] E. Pacuit and O. Roy, "Epistemic foundations of game theory," in The Stanford Encyclopedia of Philosophy, summer 2018 ed., E. N. Zalta, Ed. Metaphysics Research Lab, Stanford University, 2018.

[61] K. Madani and J. R. Lund, "A Monte-Carlo game theoretic approach for Multi-Criteria Decision Making under uncertainty," Adv. Water Resour., vol. 34, no. 5, pp. 607-616, 2011, doi: https://doi.org/10.1016/j.advwatres.2011.02.009.

[62] E. Van Damme and S. Hurkens, "Endogenous Stackelberg Leadershi," Games Econ. Behav., vol. 28, no. 1, pp. 105-129, 1999, doi: https://doi.org/10.1006/game.1998.0687.

[63] S. Jørgensen, S.-P. Sigue, and G. Zaccour, "Stackelberg leadership in a marketing channel," Int. Game Theory Rev., vol. 3, no. 1, pp. 13-26, 2001, doi: https://doi.org/10.1142/S0219198901000282.

[64] R. S. Gibbons, Game theory for applied economists. Princeton University Press, 1992.

[65] M. Fahrioglu and F. L. Alvarado, "Designing incentive compatible contracts for effective demand management," IEEE Trans. Power Syst., vol. 15, no. 4, pp. 1255-1260, 2000, doi: https://doi.org/10.1109/59.898098.

[66] M. Fahrioglu and F. L. Alvarado, "Using utility information to calibrate customer demand management behavior models," IEEE Trans. Power Syst., vol. 16, no. 2, pp. 317-322, 2001, doi: https://doi.org/10.1109/59.918305.

[67] R. Stafford, "Random vectors with fixed sum," MATLAB Central File Exchange, 2006. Available: https://au.mathworks.com/matlabcentral/fileexchange/9700-random-vectors-with-fixed-sum/ [Accessed: 4-Aug.-2020].

[68] J. Anderson, "Pulling the Plug on Network Congestion," B. A. dissertation, Department of Economics, University of Otago, Dunedin, New Zealand, 2009.

[69] P. Ralon, M. Taylor, A. Ilas, H. Diaz-Bone, and K.-P. Kairies, "Electricity storage and renewables: costs and markets to 2030," International Renewable Energy Agency, Abu Dhabi, UAE, 2017.

[70] E. Jarvis. Understanding Microgrid Categories and Business Models. 2017. Available: https://blog.se.com/renewable-energy/2017/12/15/understanding-microgrid-categories-business-models/ [Accessed: 4-Aug.-2020]. 
[71] New Zealand's Ministry of Business, Innovation, and Employment. Energy in New Zealand 19. Available: https:/www.mbie.govt.nz/dmsdocument/7040-energy-in-new-zealand-2019/ [Accessed: 4Aug.-2020].

[dataset] [72] B. Anderson, D. Eyers, R. Ford, D. G. Ocampo, R. Peniamina, J. Stephenson, K. Suomalainen, L. Wilcocks, and M. Jack. New Zealand GREEN Grid Household Electricity Demand Study 2014-2018. Colchester, Essex: UK Data Service. http://dx.doi.org/10.5255/UKDA-SN-853334.

[73] EU SCIENCE HUB. Individual mobility: From conventional to electric cars. 2015. Available: https://ec.europa.eu/jrc/en/publication/eur-scientific-and-technical-research-reports/individual-mobilityconventional-electric-cars/ [Accessed: 4-Aug.-2020].

[74] B. Anderson, R. Parker, D. Myall, H. Moller, and M. Jack, "Will flipping the fleet $\mathrm{f}^{* *} \mathrm{k}$ the grid?," in 7th IAEE Asia-Oceania Conference 2020, Auckland, New Zealand, 12-15 Feb. 2020, pp. 1-8.

[75] New Zealand's Ministry of Transport. New Zealand Household Travel Survey 2010-2013. 2014. Available: https:/www.transport.govt.nz/assets/Uploads/Research/Documents/Drivers-2014-y911Final-v3.pdf [Accessed: 4-Aug.-2020].

[76] Electricity Authority. Investigation into the Value of Lost Load in New Zealand - Report on methodology and key findings. 2013. Available: https:/www.ea.govt.nz/dmsdocument/15385electricity-authority-investigation-into-the-value-of-lost-load-in-new-zealand-report-on-methodologyand-key-findings-23-july-2013 [Accessed: 4-Aug.-2020].

[77] X. Xi and R. Sioshansi, "Using Price-Based Signals to Control Plug-in Electric Vehicle Fleet Charging," IEEE Trans. Smart Grid, vol. 5, no. 3, pp. 1451-1464, 2014, doi: https://doi.org/10.1109/TSG.2014.2301931.

[dataset] [78] U.S. Energy Information Administration. Annual Electric Power Industry Report, Form EIA861 detailed data files. [Online]. Available: https://www.eia.gov/electricity/data/eia861/ [Retrieved: 10Feb.-2020].

[79] İ. Şengör, O. Erdinç, B. Yener, A. Taşc1karaoğlu, and J. P. S. Catalão, “Optimal Energy Management of EV Parking Lots Under Peak Load Reduction Based DR Programs Considering Uncertainty,” IEEE Trans. Sustain. Energy, vol. 10, no. 3, pp. 1034-1043, 2019, doi: https://doi.org/10.1109/TSTE.2018.2859186.

[dataset] [80] CliFlo: New Zealand's National Climate Database. Available: http://cliflo.niwa.co.nz/ [Retrieved: 10-Feb.-2020].

[81] S. Mohseni and A. C. Brent, "Economic viability assessment of sustainable hydrogen production, storage, and utilisation technologies integrated into on- and off-grid micro-grids: A performance comparison of different meta-heuristics," Int. J. Hydrogen Energy, In Press, Corrected Proof, 2019, doi: https://doi.org/10.1016/j.ijhydene.2019.11.079.

[dataset] [82] The Electricity Market Information: The New Zealand Electricity Authority's wholesale database. Available: https://www.emi.ea.govt.nz/Wholesale/Reports/ [Retrieved: 10-Feb.-2020].

[83] MATLAB. Natick, MA: The MathWorks Inc, 2018. R2018b, Version 9.5.

[84] BRANZ. Energy Use in New Zealand Households. 2006. Available: https://www.branz.co.nz/cms_show_download.php?id=b1ab61dd06f50e83e6a184b29b68a989472502ed / [Retrieved: 10-Feb.-2020]. 